Accepted Manuscript

\title{
STATIC ANALYSIS OF HIGHLY ANISOTROPIC LAMINATED BEAM USING UNIFIED ZIG-ZAG THEORY SUBJECTED TO MECHANICAL AND THERMAL LOADING
}

Mehran Ghalami-Choobar, Gholamhossein Liaghat, Mojtaba Sadighi, Hamed Ahmadia Omid Razmkhah, Akbar Aboutorabi

PII: S0020-7403(17)33588-9

DOI: 10.1016/j.jjmecsci.2018.04.030

Reference: MS 4285

To appear in: International Journal of Mechanical Sciences

Received date: 18 December 2017

Revised date: 25 February 2018

Accepted date: 18 April 2018

Please cite this article as: Mehran Ghalami-Choobar, Gholamhossein Liaghat, Mojtaba Sadighi , Hamed Ahmadia Omid Razmkhah, Akbar Aboutorabi, STATIC ANALYSIS OF HIGHLY ANISOTROPIC LAMINATED BEAM USING UNIFIED ZIG-ZAG THEORY SUBJECTED TO MECHANICAL AND THERMAL LOADING, International Journal of Mechanical Sciences (2018), doi: 10.1016/j.jjmecsci.2018.04.030

This is a PDF file of an unedited manuscript that has been accepted for publication. As a service to our customers we are providing this early version of the manuscript. The manuscript will undergo copyediting, typesetting, and review of the resulting proof before it is published in its final form. Please note that during the production process errors may be discovered which could affect the content, and all legal disclaimers that apply to the journal pertain. 


\section{Highlights}

- Accurate prediction of stress filed plays an important role in highly anisotropic laminates.

- An Unified Zig-Zag Theory is developed with two primary variable under thermal environment.

- Comparison of the model predictions and that of literature indicates good agreement.

- The results show the interlaminar continuity(IC) causes more accurate stress in thin laminates

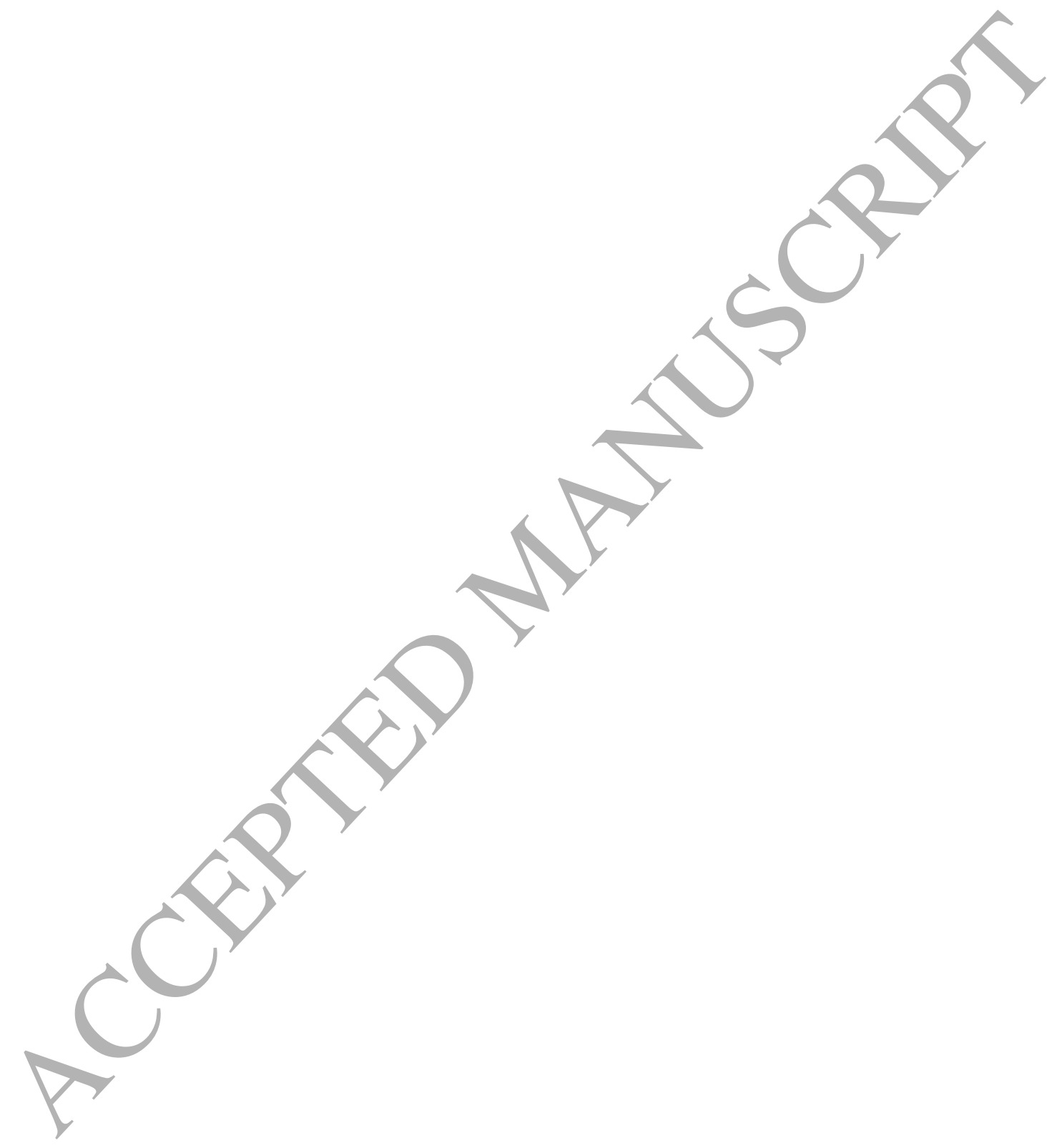




\title{
STATIC ANALYSIS OF HIGHLY ANISOTROPIC LAMINATED BEAM USING UNIFIED ZIG-ZAG THEORY SUBJECTED TO MECHANICAL AND THERMAL \\ LOADING
}

\author{
Mehran Ghalami-Choobar, Gholamhossein Liaghat* ${ }^{1,2}$, Mojtaba Sadighi ${ }^{3}$, Hamed Ahmadi ${ }^{1}$ Omid Razmkhah $^{4}$, Akbar \\ Aboutorabi $^{5}$ \\ ${ }^{1}$ Department of Mechanical Engineering, Tarbiat Modares University (TMU), Tehran, Iran \\ ${ }^{2}$ School of Mechanical \& Aerospace Engineering, Kingston University, London, England \\ ${ }^{3}$ Mechanical Engineering Faculty, Amirkabir University of Technology, Tehran, Iran \\ ${ }^{4}$ Department of Mechanical Engineering, Coventry University, United Kingdom \\ ${ }^{5}$ School of Business \& Mathematics, Richmond American University, London, United Kingdom
}

\begin{abstract}
In the present study, static behavior of short hybrid laminate beams was investigated using a unified zig-zag theory (ZZT) containing various beam theories as special cases. This theory satisfies transverse shear stresses continuity in the interface of layers via piece-wise continuous arbitrary shape functions. The principle of virtual work was employed to derive unified equilibrium equations and suitable boundary conditions. The present theory obviates the need for stress recovery for continuous transverse stresses. A general solution was presented to analyse high transversely anisotropic laminates under several kinds of transverse loads (general lateral, sinusoidal and point load) and non-linear thermal loads. The validity of this model is demonstrated by comparison of its predictions and good agreement with published results in literature. Numerical examples were given to investigate the impact of the transverse anisotropy on displacement, strain and stress fields through the thickness. The results show that the piece-wise continuous exponential and sinusoidal shape functions provide more accurate transverse stress distribution in comparison with other shape functions. In addition, the results show that the continuity of transverse shear stress through the thickness plays an important role in analysing transversely anisotropic laminated beams. A comparison of present ZZT and existing exact elasticity solutions shows that the current theory is simple and efficient.
\end{abstract}

Keywords: Zig-Zag theories; Hybrid laminate; interlaminar shear stress continuity, Equivalent Single Layer; Closed-form solution

*Faculty of Mechanical Engineering, Tarbiat Modares University, Jalal Ale Ahmad Highway, Tehran, Iran P.O.B: 14115-111. E-Mail:ghlia530@modares.ac.ir, g.liaghat@kingston.ac.uk 


\section{Introduction}

In recent decades, the application of hybrid composite laminates and sandwich structures has found popularity in aerospace and automobile industries [1-3]due to their superior mechanical properties such as specific stiffness, strength and fatigue characteristics compared to the traditional structures[4,5]. As a result, the utilization of hybrid and Carbon reinforced composites is expected to increase in the coming years [6].

Accurate prediction of stress distribution through the body plays an important role in primary structure design[7]. Furthermore, thickening the multilayer composite to prevent damage in critical points exacerbates non-classical effects such as transverse shear and normal deformation [6]. For instance, Euler-Bernoulli Deformation Theory (EBDT) and Kirchhoff-Love plate/shell theory provide an inaccurate prediction of global deflection and local effects [8]. Although other Equivalent Single Layers (ESL) theories such as First-order Shear Deformation Theory(FSDT), High-order Shear Deformation Theory(HSDT) and Advanced High Order Theories $[9,10]$ offer some improvements, they suffer from drawbacks of inaccurate prediction in some high transversely anisotropic laminates. On the other hand, in case of laminates having large numbers of layers, Layer-Wise (LW) models are computationally very expensive in spite of providing highly accurate results [11]. Therefore, developing novel theoretical models to capture non-classical effects is vital to produce the reliable design.

Zig-Zag theories (ZZT) combine the low computational cost of ESL theories and the ability of LW theories to model laminates having layers with completely different material properties [9]. This theory incorporates piecewise continuous displacement field shown in multilayer composites. The variation of slope through thickness due to transverse anisotropy is known as Zig-Zag (ZZ) effect (Fig. 1). Interlaminar continuity(IC)[12] for transverse stresses causes rapid changes in the slope of in-plane displacement field. ZZT includes three different and independent contributions: Lekhnitskii Multilayered Theory (LMT), Ambartsumian Multilayered Theory (AMT) and Reissner Multilayered Theory (RMT) [6,13]. Lekhnitskii apparently proposed a ZZT for the first time [13]. Ambartsumian developed a ZZT assuming a parabolic distribution for transverse shear stress [14]. Later on, Di Sciuva presented a displacement theory to enhance first-order shear deformation theory to take into account ZZ effects [15]. Tessler et al developed a refined zigzag theory RZT to overcome shortcomings of Di Sciuva formulation [16]. Similarly, Murakami presented an alternative method to improve FSDT by including a geometric zigzag function which is known as Murakami's ZZ function (MZZF)[13,17]. Carrera presented a unified description of several theories including ESL, LW and ZZ effects. The finite element matrices derived in 
a unified manner and vast numerical examples have been given [18,19]. MZZF employs an independent parabolic function for displacement and shear stress distribution via a mixed variational calculus method. Brischetto et al applied MZZF to sandwich panels[20]. Gherlone et al [1] studied the mixed formulation of MZZF in comparison with displacement-based MZZF, RZT and Timoshenko beam. They showed RZT is more accurate for arbitrary lay-ups by considering the ZZ effects. Groh and Weaver [6] investigated displacementbased and mixed formulation with Reddy shape function and MZZF. Furthermore, they proposed a unified general theory based on Hellinger-Reissner mixed formulation to capture non-classical effect due to highly heterogeneous multilayers[21,22].

Rodrigues et al. investigated bending, free vibration and buckling of laminated plates using MZZF in using local collocation method based on radial basis functions[23]. Kulkarni and Kapuria developed a quadrilateral element for static and free vibration analysis of composite and sandwich plats. They validated the finite formulation by comparing with the analytical Navier solution for simply supported plates[24,25]. Neves et al. employed Carrera's Unified Formulation (CUM) to study thin and thick functionally graded sandwich plates. Also, they considered thickness stretching effect in the model[26]. Sahoo and Singh presented an efficient element based on a new trigonometric ZZT for free vibration and búckling of laminated and sandwich plates[27]. Pandit et al proposed an improved high order zig-zag theory for static analysis of laminated sandwich plate with compressible soft core[28].

In addition to mentioned works in the linear elastic domain, a few attempts have employed $\mathrm{ZZ}$ to model delamination damage in multilayer composites[29]. Groh et al used the cohesive zone approach to predict the initiation and propagation of delamination in cross-ply composite beams and compare the predictions with those of experimental test [30]. Eijo et al. developed beam and plate/shell element to model delamination (mode II and III) in laminated composites using an isotropic damage model[31,32].

In this paper, a general solution of unified ZZT for arbitrary shape function is presented, where a piece-wise continuous arbitrary function is assumed as distribution of transverse shear stresses through the thickness. Interlaminar continuity of transverse stress and displacement can be applied via the assumed distribution. The unified governing equations and boundary conditions are derived using the principle of the virtual work, and the Navier-type and closed-form solutions are given for the proposed beam theory subjected to mechanical and thermal loads. By comparing present model results with those reported in literature, the validity of solutions is 
confirmed. Furthurmore, other numerical results from this work are given to investigate the impact of the transverse anisotropy on displacement and stress fields along the beam length and through the thickness.

\section{Theoretical formulations}

\subsection{Transverse shear stress and displacement field}

In the present study, a composite laminate is considered which is illustrated in Fig. 2. The x-and y-axes are assumed along the length $(L)$ and the thickness $(h)$, respectively. The unified transverse shear stress field of $k_{\text {th }}$ layer at any point $(x, z)$ for present ZZT theory is given by

$\left.\tau_{x z}^{(k)}=G\left\{A^{(k)}+m^{(k)}\left(\frac{d \varnothing}{d z}-1\right)\right)\right\} \bar{\gamma}_{x z}(x)$

where $G, A^{(k)}, m^{(k)}$ and $\bar{\gamma}_{x z}$ are effective shear modulus, shear stress layer-wise constant, modification factor of layer $\mathrm{k}$ and transverse shear strain, respectively. A posteriori function $\varnothing(z)$ incorporates the through the thickness distribution of transverse shear stress. The effective shear modulus and modification factor can be defined as

$m^{(k)}=e^{(k)}\left(g^{(k)}+\frac{1}{g^{(k)}}-1\right)$

where $e^{(k)}$ can be expressed by

$e^{(k)}=\frac{\bar{Q}^{(k)}}{E}$

$E=1 / h \sum_{k=1}^{N} t^{(k)} \bar{Q}^{(k)}$

and $g^{(k)}$ is given by

$$
\begin{aligned}
& g^{(k)}=\frac{G}{G_{x z}^{(k)}} \\
& G=\left[\frac{1}{h} \sum_{k=1}^{N} \frac{t^{(k)}}{G_{x z}{ }^{(k)}}\right]^{-1}
\end{aligned}
$$


where $\bar{Q}^{(k)}, G_{x z}^{(k)}$ and $t^{(k)}$ are reduced stiffness, transverse shear modulus, and thickness of $\mathrm{k}_{\mathrm{th}}$ layer. It should be noted that Eq. (1) is the unified form of recent formula proposed by literature [6]. Groh and Weaver's formula is a piece-wise continues parabola distribution based on Reddy High order shear theory.

$$
\tau_{x z}^{(k)}=G\left\{A^{(k)}-\frac{4}{t^{2}} e_{(k)}\left(g_{k}+\frac{1}{g_{k}}-1\right) z^{2}\right\} \bar{\gamma}_{x z}(x)
$$

It should be noted that transverse shear strain, $\bar{\gamma}_{x z}$, is measured on the mean-line of the beam.

$\bar{\gamma}_{x z}=\mathrm{w}_{, \mathrm{x}}-\psi$

where $\mathrm{w}$ and $\psi$ are transverse displacement and section rotation on the mean-line of the beam. In both Eqs. (1) and (7), shear stress layer-wise constants, $A^{(k)}$, are determined by satisfying transverse stress continuity. The free surface and stress continuity conditions are given by

$$
\begin{aligned}
& \tau_{x z}^{(1)}\left(z_{0}\right)=0 \\
& A^{(1)}=-m^{(1)}\left(\frac{d \varnothing}{d z}-1\right)
\end{aligned}
$$

\section{And}

$$
\begin{aligned}
& \tau_{x z}^{(k)}=\tau_{x z}^{(k+1)} \\
& A^{(k+1)}=A^{(k)}+\left(m^{(k)}-m^{(k+1)}\right)\left(\frac{d \varnothing}{d z}-1\right)
\end{aligned}
$$

Assuming linear strain-displacement relationship, unified displacement field $u_{x}^{k}(x, z)$ for present ZZT may be written as follows:

$$
\begin{aligned}
& \left.u_{x}^{(k)}(x, z)=-z w_{, x}(x)+g^{(k)}\left\{z A^{(k)}+m^{(k)}(\varnothing-z)\right)\right\} \bar{\gamma}_{x z}+c^{(k)} \bar{\gamma}_{x z} \\
& u_{z}(x, z)=w(x)
\end{aligned}
$$

The function $\varnothing(z)$ represents shape functions defining the distribution of displacement and stress function through the thickness. It should be noted that the present ZZT is developed based on Reddy's high order theory which suffers from inconsistency in modeling clamped edges[33]. In this high order theories, enforcing $w_{, x}=0$ at edges causes $\bar{\gamma}_{x z}=0$, which does not match the 3D elasticity solution. The displacement field of various ZZTs may be obtained using shape functions given in Table 1. It can be noted the displacement field of HSDT is obtained by setting:

$$
A^{(k)}=c^{(k)}=0, \quad g^{(k)}=m^{(k)}=1
$$

In Eq. (13), displacement layer-wise constants $c^{(k)}$ are determined by enforcing displacement continuity. The neutral axis location and continuity condition are given by:

$$
u_{x}^{\left(k_{0}\right)}=0
$$


$c^{\left(k_{0}\right)}=0$

And

$u_{x}^{(k)}=u_{x}^{(k+1)}$

$c^{(k)}=\sum_{i=k_{0}+1}^{k}\left[\left(g^{(i-1)} A^{(i-1)}-g^{(i)} A^{(i)}\right) z_{i-1}-\left(g^{(i-1)} m^{(i-1)}-g^{(i)} m^{(i)}\right)(\varnothing-z)_{i-1}\right]$

$c^{(k)}=\sum_{i=k}^{k_{0}-1}\left[\left(g^{(i+1)} A^{(i+1)}-g^{(i)} A^{(i)}\right) z_{i}-\left(g^{(i+1)} m^{(i+1)}-g^{(i)} m^{(i)}\right)(\varnothing-z)_{i}\right]$

where the neutral axis is located within layer $k_{0}$.

\subsection{Deriving equilibrium equations}

The principle of virtual work is employed to derive governing equation,

$$
\begin{aligned}
& \delta \Pi_{P V D}=\iint_{0}^{L} \iint_{S}\left[\sigma_{x}^{H(k)} \delta \varepsilon_{x}^{G(k)}+\tau_{x z}^{H} \delta \gamma_{x z}^{G(k)}\right] d S d x-\int_{0}^{L} q \delta w d x-\int_{S_{1}}\left[\hat{\sigma}_{x} \delta u_{x}+\hat{\tau}_{x z} \delta w\right] d S_{1} \\
& =\int_{0}^{L}\left(M_{x} \delta w_{, x x}+L_{x} \delta \bar{\gamma}_{x z, x}+Q_{x} \delta \gamma_{x z}\right) d x-\int_{0}^{L} q d x \delta w-\hat{M}_{x} \delta w_{, x}-\hat{L}_{x} \delta \gamma_{x z}-\hat{V_{x}} \delta w
\end{aligned}
$$

where $\hat{\sigma}_{x}$ and $\hat{\tau}_{x z}$ are stress tractions applied to the boundaries. The superscripts $\mathrm{G}$ and $\mathrm{H}$ indicate the stress or strains which are calculated using geometric relationship and Hook law, respectively. Bending moments and shear forces are defined in Eqs. (22) to (25) below:

$$
\begin{aligned}
& M_{x}=\int_{-t / 2}^{t / 2} z \sigma_{x}^{\mathrm{H}(k)} d z \\
& L_{x}=\int_{-t / 2}^{t / 2} f^{(k)} \sigma_{x}^{\mathrm{H}(k)} d z \\
& Q_{x}=\int_{-t / 2}^{t / 2} g^{(k)} s^{(k)}(z) \tau_{x z}^{\mathrm{H}(k)} d z \\
& \hat{V_{x}}=\int_{-t / 2}^{t / 2} \hat{\tau}_{\mathrm{xz}} d z
\end{aligned}
$$

The normal strain $\varepsilon_{x}^{\mathrm{G}(k)}$ and transverse shear strain $\gamma_{x z}^{\mathrm{G}(k)}$ are determined as follows

$\varepsilon_{x}^{\mathrm{G}(k)}(x, z)=-z w_{, x x}(x)+f^{(k)}(z) \bar{\gamma}_{x z, x}(x)-\alpha_{x x} \Delta T$

$\gamma_{x z}^{\mathrm{G}(k)}(x, z)=g^{(k)} s^{(k)}(z) \bar{\gamma}_{x z}(x)$

where $\alpha_{\mathrm{x} x}$ is the coefficient of linear thermal expansion in the $\mathrm{x}$-direction. The shear function $s^{(k)}(z)$ is given by:

$$
s^{(k)}(z)=A^{(k)}+m^{(k)}\left(\varnothing_{, z}-1\right)
$$

and displacement function $f^{k}(z)$ is given by: 
$f^{k}(z)=g^{(k)}\left(z A^{(k)}+m^{(k)}(\varnothing-z)\right)+c^{(k)}$

The nonlinear thermal load $\Delta T$ subjected to the beam is assumed to be [34]:

$\Delta T=T_{1}(x)+\frac{\mathrm{z}}{\mathrm{h}} \mathrm{T}_{2}(\mathrm{x})+\frac{(\varnothing-z)}{\mathrm{h}} \mathrm{T}_{3}(\mathrm{x})$

Minimizing energy functional $\delta \Pi_{\mathrm{PVD}}$ using variational calculus gives the governing equations as:

$M_{x, x x}+q=0$

$L_{x, x}-Q_{x}=0$

and boundary conditions as:

$$
\begin{aligned}
& \delta w=0 \text { or } M_{x, x}-\hat{V}_{x}=0 \\
& \delta w_{, x}=0 \text { or } M_{x}-\hat{M}_{x}=0 \\
& \delta \bar{\gamma}_{x z}=0 \text { or } L_{x}-\hat{L}_{x}=0
\end{aligned}
$$

The relationship between stress resultant forces and strains are expressed then as:

$$
\left(\begin{array}{c}
M_{x} \\
L_{x} \\
Q_{x}
\end{array}\right)=\left[\begin{array}{ccc}
D & D^{\gamma} & 0 \\
D^{\gamma} & D^{\gamma \gamma} & 0 \\
0 & 0 & J
\end{array}\right]\left(\begin{array}{c}
w_{, x x} \\
\bar{\gamma}_{x z, x} \\
\gamma_{x z}
\end{array}\right)-\left(\begin{array}{c}
M_{x}^{T} \\
L_{x}^{T} \\
0
\end{array}\right)
$$

where components of stiffnesses of the beam can be written by:

$$
\begin{aligned}
& \left(\begin{array}{c}
\mathrm{D} \\
D^{\gamma} \\
D^{\gamma / \gamma}
\end{array}\right)=\sum_{k=1}^{N} \int_{z^{(k-1)}}^{z^{(k)}} \overline{\mathrm{Q}}^{(\mathrm{k})}\left(\begin{array}{c}
z^{2} \\
z f^{(k)} \\
f^{(k) 2}
\end{array}\right) d z \\
& J=\sum_{k=1}^{N} \int_{z^{(k-1)}}^{z^{(k)}} G g^{(k)}\left(s^{(k)}(z)\right)^{2} d z
\end{aligned}
$$

and $M_{x}^{T}$ is thermal resultant force:

$$
\begin{aligned}
& M_{x}^{T}=\sum_{k=1}^{N} \int_{z^{k-1}}^{z^{k}} \overline{\mathrm{Q}}^{(\mathrm{k})} \alpha_{\mathrm{x} x} \Delta T z d z=F T_{1}(x)+H T_{2}(x)+K T_{3}(x) \\
& L_{x}^{T}=\sum_{k=1}^{N} \int_{z^{k-1}}^{z^{k}} \overline{\mathrm{Q}}^{(\mathrm{k})} \alpha_{\mathrm{x} x} \Delta T f^{(k)} d z=F^{f} T_{1}(x)+H^{f} T_{2}(x)+K^{f} T_{3}(x)
\end{aligned}
$$

where

$$
\begin{aligned}
& \left(\begin{array}{c}
\mathrm{F} \\
H \\
K
\end{array}\right)=\sum_{k=1}^{N} \int_{z^{(k-1)}}^{z^{(k)}} \overline{\mathrm{Q}}^{(\mathrm{k})} \alpha_{x}\left(\begin{array}{c}
z \\
z^{2} / h \\
z f^{(k)} / h
\end{array}\right) d z \\
& \left(\begin{array}{c}
\mathrm{F}^{f} \\
H^{f} \\
K^{f}
\end{array}\right)=\sum_{k=1}^{N} \int_{z^{(k-1)}}^{z^{(k)}} \overline{\mathrm{Q}}^{(\mathrm{k})} \alpha_{x}\left(\begin{array}{c}
f^{(k)} \\
z f^{(k)} / h \\
f^{(k)^{2}} / h
\end{array}\right) d z
\end{aligned}
$$

Substituting the stress resultant of Eq. (36) into Eqs. (31) and (32) yields the explicit form of governing equations: 


$$
\begin{aligned}
& -D w_{, x x x x}+D^{\gamma} \gamma_{z x, x x x}+M_{x, x x}^{T}+q=0 \\
& -D^{\gamma} w_{, x x x}+D^{\gamma \gamma} \gamma_{z x, x x}+L_{x, x}^{T}-J \gamma_{z x}=0
\end{aligned}
$$

\subsection{Series solution}

An analytical solution is obtained for a simply supported beam subjected to general load $\mathrm{q}$ in thermal environment satisfying the following boundary conditions:

$w=0, M_{x}=0, L_{x}=0 \quad$ at $\quad x=0, L$

The solution is assumed as

$$
\begin{aligned}
& w=\sum_{n=1}^{\infty} W_{n} \sin \left(\frac{n \pi x}{L}\right) \\
& \bar{\gamma}_{x z}=\sum_{n=1}^{\infty} \Gamma_{n} \cos \left(\frac{n \pi x}{L}\right)
\end{aligned}
$$

$q=\sum_{n=1}^{\infty} q_{n} \sin \left(\frac{n \pi x}{L}\right)$

where $q_{n}$, Fourier series coefficients, are given by [35]

$q_{n}=\frac{2}{L} \int_{0}^{L} q \sin \left(\frac{n \pi x}{L}\right) \mathrm{dx}$

for uniform load $q=q_{0}$

$$
q_{n}=\frac{4 q_{0}}{n \pi}, n=1,3,5, \ldots
$$

and sinusoidal load $q=q_{0} \sin \left(\frac{n \pi x}{L}\right)$

$q_{1}=1, q_{2-n}=0$

and point load $q=q_{0} \delta(x-L / 2)$

$q_{n}=\frac{2 q_{0}}{L} \sin \left(\frac{n \pi}{2}\right)$

Substituting Eqs. (44) \& (45) \& (46) into Eqs. (41) \& (42) yields following expression:

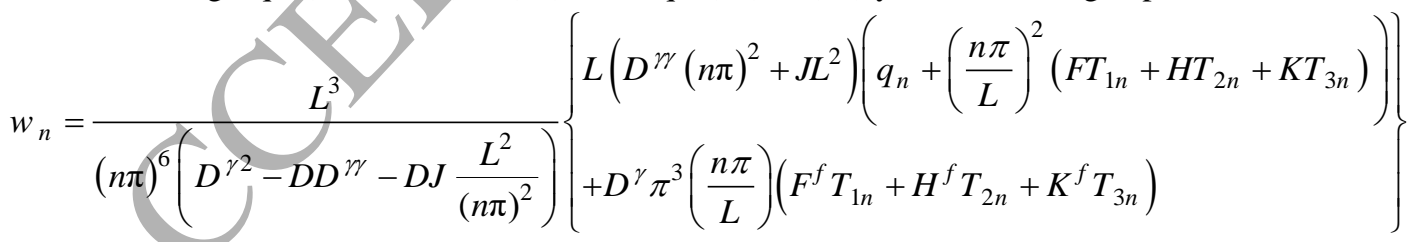

The coefficients $T_{1 n}, T_{2 n}, T_{3 n}$ are defined using Fourier sin series of thermal loads

$$
\begin{aligned}
& T_{1}=\sum_{n=1}^{\infty} T_{1 n} \sin \left(\frac{n \pi x}{L}\right) \\
& T_{2}=\sum_{n=1}^{\infty} T_{2 n} \sin \left(\frac{n \pi x}{L}\right) \\
& T_{3}=\sum_{n=1}^{\infty} T_{3 n} \sin \left(\frac{n \pi x}{L}\right)
\end{aligned}
$$

Where 
$T_{1 n}=\frac{2}{L} \int_{0}^{L} \mathrm{~T}_{1}(x) \sin \left(\frac{n \pi x}{L}\right) \mathrm{dx}$

$T_{2 n}=\frac{2}{L} \int_{0}^{L} \mathrm{~T}_{2}(x) \sin \left(\frac{n \pi x}{L}\right) \mathrm{dx}$

$T_{3 n}=\frac{2}{L} \int_{0}^{L} \mathrm{~T}_{3}(x) \sin \left(\frac{n \pi x}{L}\right) \mathrm{dx}$

In case of sinusoidal temperature field, coefficients $T_{1 n}, T_{2 n}, T_{3 n}$ are given by:

$T_{1 n}, T_{2 n}, T_{3 n}=1$ for $n=1$

To study the performance of the present ZZT, transverse displacement W, Eq. (51) for $\Delta T=0$, is divided by that of the classical beam theory $w_{n c}=\frac{L^{4} q_{n}}{\pi^{4} D}$. The non-dimensional deflection ratio, $\frac{w_{n}}{w_{n c}}$, may be expressed as:

$\frac{w_{n}}{w_{n c}}=\frac{\left(\frac{D^{\gamma \gamma}(n \pi)^{2}}{J L^{2}}+1\right)}{\left(1-\frac{D^{\gamma 2}}{D J L^{2}}(n \pi)^{2}+\frac{D^{\gamma \gamma}}{J L^{2}}(n \pi)^{2}\right)}$

Eq. (59) shows that factors of $V_{1}=\frac{D^{\gamma 2}(n \pi)^{2}}{D J L^{2}}$ and $V_{2}=\frac{D^{\gamma / \gamma}(n \pi)^{2}}{J L^{2}}$ play an important role in static response of a multilayer composite. Furthermore, the equation indicates that the effects of $\mathrm{ZZ}$ phenomenon are greater for higher modes $(n>1)$. When $\frac{D^{\gamma 2}}{D J L^{2}} \ll 1$ and $\frac{D^{\gamma \gamma}}{J L^{2}} \ll 1$ the transverse shear strain effects are negligible and EBDT is satisfactory.

\subsection{Exact solution}

Integrating the first equation of governing equations (Eqs. (41) \& (42) for point load and nonlinear thermal load) yields following:

$$
\begin{aligned}
& +D W_{, x x x}-D^{\gamma} \gamma_{z x, x x}-C_{3}-(F+H+K) \frac{L}{\pi} \cos \left(\frac{\pi x}{L}\right)=0 \\
& -D^{\gamma} W_{, x x x}+D^{\gamma \gamma} \gamma_{z x, x x}+\left(F^{f}+H^{f}+K^{f}\right) \frac{\pi}{L} \cos \left(\frac{\pi x}{L}\right)-J \gamma_{z x}=0
\end{aligned}
$$

where $C_{3}$ is integral constant. Through a simple combination of Eq. (60) \& (61), the following differential equation for $\bar{\gamma}_{\mathrm{xz}}(\mathrm{x})$ is obtained

$$
\left(D^{\gamma \gamma} D-D^{\gamma} D^{\gamma}\right) \gamma_{z x, x x}-J D \gamma_{z x}-D^{\gamma}\left(C_{3}+\left(\left(F^{f}+H^{f}+K^{f}\right) \frac{\pi}{L}+(F+H+K) \frac{L}{\pi}\right) \cos \left(\frac{\pi x}{L}\right)\right)=0
$$

The solution of Eq. (61) can be written as follows: 
$\gamma_{z x}=C_{1} \sinh (\omega x)+C_{2} \cosh (\omega x)-\frac{D^{\gamma} C_{3}}{D J}-C^{t h} \cos \left(\frac{\pi x}{L}\right)$

where

$$
\begin{aligned}
& \omega=\sqrt{\frac{D J}{D^{\gamma \gamma} D-D^{\gamma} D^{\gamma}}} \\
& C^{t h}=D^{\gamma} \frac{(F+H+K) L / \pi+\left(F^{f}+H^{f}+K^{f}\right) \frac{\pi}{L}}{\left(\left(D^{\gamma /} D-D^{\gamma} D^{\gamma}\right)\left(\frac{\pi}{L}\right)^{2}-J D\right)}
\end{aligned}
$$

and $C_{1}, C_{2}, C_{3}$ will be determined by applying boundary conditions. Substituting Eq. (62) into Eq. (60) and integrating, the transverse deflection $\mathrm{W}$ can be obtained as:

$$
\begin{aligned}
& W=\frac{D^{\gamma}}{D \omega} \frac{\left(C_{1} \sinh (\omega x)+C_{2} \cosh (\omega x)\right)+C_{3} x^{3}}{6}+\frac{C_{4} x^{2}}{2} \\
& +C_{5} x+C_{6}\left(\frac{L}{\pi} C^{\text {th }}-\frac{(F+H+K)}{D}\left(\frac{L}{\pi}\right)^{4}\right) \sin \left(\frac{\pi x}{L}\right)
\end{aligned}
$$

Where constants $C_{1-6}$ are determined boundary conditions. Due to the symmetry of model, one half of the beam is considered to obtain a solution associated with three point bending regarding corresponding boundary conditions (Fig. 3). Therefore, appropriate boundary condition is given as follows

$$
W(0)=0, W_{, x}\left(\frac{L}{2}\right)=0, \psi\left(\frac{L}{2}\right)=0, M_{x}(0)=0, L_{x}(0)=0, M_{x, x}\left(\frac{L}{2}\right)=\frac{q}{2}
$$

After some algebraic manipulation, the following equation is obtained for the beam subjected to point load q:

$$
W=\frac{q L^{3}}{D}\left(\frac{D^{\gamma 2}}{2 L^{3} D J \omega \cos (\omega L / 2)} \sinh (\omega x)-\frac{75}{90}\left(\frac{x}{L}\right)^{3 /}+\left(\frac{1}{16}+\frac{D^{\gamma 2}}{2 L^{2} D J}\right) \frac{x}{L}\right)
$$

For clamped geometry, the boundary conditions are:

$W(0)=0, W_{, x}\left(\frac{L}{2}\right)=0, \psi\left(\frac{L}{2}\right)=0, W_{, x}(0)=0, \psi(0)=0, M_{x, x}\left(\frac{L}{2}\right)=\frac{q}{2}$

Therefore the following equation is obtained:

$W=\frac{q L^{3}}{D}\left(\begin{array}{l}\frac{D^{\gamma^{2}\left(\cosh \left(\frac{\omega L}{2}\right)-1\right)}}{2 L^{3} D J \omega \sinh \left(\frac{\omega L}{2}\right)} \cosh (\omega x)-\frac{D^{\gamma 2}}{2 L^{3} D J \omega} \sinh (\omega x)-\frac{1}{9}\left(\frac{x}{L}\right)^{3} \\ +\frac{1}{12}\left(\frac{x}{L}\right)^{2}+\frac{D^{\gamma 2}}{2 L^{2} D J} \frac{x}{L}-\frac{D^{\gamma 2}\left(\cosh \left(\frac{\omega L}{2}\right)-1\right)}{2 L^{3} D J \omega \sinh \left(\frac{\omega L}{2}\right)}\end{array}\right)$

For the sake of simplicity, constants $C_{1-6}$ for the beam in thermal environment $(\Delta T \neq 0)$ are not given here.

\section{Numerical results and discussions}


The unified zigzag theory having different shape functions (See Table 1) derived in the previous section is used to investigate the static behavior of transversely anisotropic beams. A comparison study is carried out to show accuracy of formulation and its solutions. In this section, some examples are given to study transverse anisotropy and zig-zag phenomenon. The non-dimensional quantities are defined as:

$$
\begin{aligned}
& \underline{z}=\frac{z}{h}, \underline{x}=\frac{x}{L} \\
& U=\frac{u_{x}(x, z)}{\frac{q_{0} h}{E_{2}}+\alpha T_{2} L^{2}} \\
& W=\frac{w}{\frac{q_{0} L^{4}}{E_{2} h^{3}}+\frac{\alpha T_{2} L^{2}}{10 h}} \text { or } W=\frac{w}{h} \\
& \sigma=\frac{\sigma_{x}^{H(k)}}{q_{0} L^{2}} \frac{\tau^{2}}{h^{2}(k)} \\
& \tau=\frac{E_{2 z} \alpha T_{2} L^{2}}{q_{0}}
\end{aligned}
$$

For validation purposes, results from present theory for $\varnothing=$ Parabolic shape function is compared with those reported by Groh and Weaver [6]. A beam with lay-up 0/90/0/90/0, length 8 in and thickness 1 in subjected to a sinusoidal load is considered (Laminate A). Table 2 shows the material properties of lamina used in Laminate A. Fig. 4 illustrates non-dimensional transverse shear stress through the thickness of the multilayer. The results of the present theory with $\varnothing=$ Parabolic shape function match with those of reference [6] showing the accuracy of presented formulations and solutions.

Another comparison analysis also is carried out with Abaqus Finite analysis (FEA) package [36] for laminate B (See Table 3). A thick beam with lay-up 90/0/0/90, length $6.35 \mathrm{~m}$ and thickness $2.79 \mathrm{~m}$ subjected to a sinusoidal load $(\mathrm{q}=1 \mathrm{e} 3 \mathrm{~N} / \mathrm{m})$ is considered. A shell-type element was employed via Abaqus $\backslash$ Standard. Mesh convergence studies were carried out to achieve accurate results. Fig. 5 compares non-dimensional transverse shear stress distribution along the beam length predicted by the present theory for $\varnothing=$ exponential with that of FEA software. A good agreement can be observed in the figure between the present theory prediction and result of FEA software. It should be noted the present theory has the added advantages of being simpler and faster to obtain an accurate result due to have closed-form solution.

Table 4 compares non-dimensional displacements and stresses for three and five layers symmetric cross-ply laminated beams for aspect ratio 8 . The results show the sufficient accuracy of the present ZZT including the all 
shape functions $\varnothing(\mathrm{z})$ (Table 1) for non-dimensional displacement. However, all ZZTs including Parabolic, Sinusoidal, and Exponential shape functions overestimate normal and shear stresses. The results indicate that the sinusoidal and parabolic shape functions provide more accurate results for shear stress of three layers and five layers laminates, respectively.

In another comparison, a simply supported laminated beam $(0 / 90 / 0)$ is studied by varying the aspect ratio from 10 to 100 . Table 5 compares the non-dimensional displacements and stresses with those of some different shear deformation theories as specified in the table. The results show the accuracy of the present Unified ZZTresults in comparison with those theories including more degrees of freedom.

Fig. 6 depicts variation of transverse shear stress field through the thickness the thickness in comparison with those of Chakrabarti et al [38] and Pagano (3D Elasticity) [39]. This 2 degrees of freedom (DOFs) ZZT predicts the shape of the transverse shear stress simply, however, reference [38] involving 9 DOFs provides only slightly more precise results.

Table 6 and 7 compare displacements and stresses for isotopic, unidirectional and symmetric cross-ply laminate for aspect ratio 10 and 4 , respectively. The results obtained by the present theory for an isotropic composite laminate beam are in good agreement with HSDT, FSDT, and EBDT for aspect ratio 10. In-plane displacements obtained by ZZT for isotropic and unidirectional laminated beam are comparable with that of HSDT for aspect ratio 10. Transverse displacements obtained by HSDT and FSDT are nearly identical for aspect ratio 10 and 4. HSDT and FSDT underpredict the in-plane normal stresses for unidirectional and symmetric cross-ply laminated beams. Table 6 and 7 confirm that the higher non-dimensional parameters $V_{1}$ and $V_{2}$ cause more differences between ZZT and other theories.

Fig. 7 shows the distribution of transverse shear stress through the thickness obtained using the present ZZT with different shape functions (See Table 1) for laminate A subjected to sinusoidal load [6]. It can be observed that the sinusoidal function provides more accurate prediction in comparison with parabolic and exponential shape functions. Furthermore, the shape function introduced by Reddy [37] and Ambartsumian[14] result in nearly the same stress distribution.

Fig. 8 compares the distribution of the non-dimensional transverse shear stress through the thickness obtained using ZZT, HSDT, and EBDT for laminate A. The stress field distribution obtained using HSDT changes suddenly at interfaces in contrast with present ZZT. Furthermore, EBDT predicts no shear stress and it needs 
recovery using elasticity governing equations. Fig. 8 compares normal stress distribution through thickness calculated using ZZT, HSDT, and EBDT. For top and bottom faces of the beam, the relative difference of EBDT and HSDT predictions compared to that of ZZT are $3.1 \%$ and $12.9 \%$, respectively. It can be concluded that the HSDT predicts accurately the normal stress distribution in spite of poor prediction accuracy of transverse shear stress.

Fig. 10 demonstrates the distribution of non-dimensional transverse deflection for laminate A subjected to sinusoidal load with simply supported boundary condition along the beam length. Only one half of the beam is considered $\mathrm{x}=0$ to $\mathrm{L} / 2$ due to the beam symmetry. The distribution in Fig. 10 shows the difference of the deflection obtained using ZZT, HSDT, and EBDT for the studied beam. This indicates that using ZZT results in achieving more accuracy in deflection calculation.

Fig. 11 (a), (b) depict the distribution of the in-plane displacement field through the thickness of simply supported thick beam (Laminate A) at $\mathrm{x}=0$ subjected to uniform and point loadings, respectively. The results obtained by HSDT and present ZZT are in close agreement with each other whereas FSDT and EBDT predict the displacements incorrectly for impulse load. Also, Fig 10 (c), (d) illustrate the variation of transverse shear stress through the thickness. The difference between results obtained by various theories indicates the great significance of shear effects for impulse load. Fig. 12 (a), (b) indicate the variation of in-plane displacement field across the thickness for the thick beam(Laminate A) at $\mathrm{x}=\mathrm{L} / 4$ subjected to point loading for simply supported and clamped boundary conditions. The results obtained by HSDT are much higher than those of FSDT and present ZZT. Figure 11 (c), (d) show distribution of transverse shear stresses through the thickness for thick beam (Laminate A) at $\mathrm{x}=\mathrm{L} / 4$ subjected to point loading for simply supported and clamped boundary conditions. One can see that dístribution of transverse shear stresses are similar at $\mathrm{x}=\mathrm{L} / 4$ because of the equal shear force of at $\mathrm{x}=\mathrm{L} / 4$ far from boundary edges.

Fig. 13 denotes the distribution of the punch force, F, against midpoint deflection of the beam calculated using ZZT, HSDT, and EBDT. The figure shows that EBDT overestimates the punch force compared to HSDT and ZZT. The present ZZT offers more accurate value of the punch force because of enforcing IC condition and similarity to 3D Elasticity solutions.

\section{Conclusion}


In the present study, static analysis of transversely anisotropic thick beams was investigated using a Unified ZZT subjected to mechanical and thermal loadings. The present unified zig-zag theory contains various beam theories via general shape function. The proper governing equations and boundary conditions were obtained using virtual work principle. The present Unified ZZT provides accurate transverse shear stress using constitutive equations and obviates the stress recovery process via 3D Elasticity equations. The results for $\varnothing$ $=$ Parabolic function were obtained as a special case and compared to those of the available literature. Another comparison was carried out with ABAQUS finite element analysis package. The normal stress and transverse shear stresses were compared with that of HSDT and EBDT for the sinusoidal load. Another study was performed on beam subjected to point load. Comparison of obtained results for beam under point load indicates major difference between transverse deflections obtained using ZZT, HSDT, and EBDT. It was observed that enforcing IC condition has a profound effect on the accurate prediction of those distributions for cross-ply laminates. The results show the present theories have the advantages of being simpler compared to 3D Elasticity solution in order to obtain accurate results.

\section{Acknowledgement}

The authors are grateful to the Tarbiat Modares University (TMU) for their financial support.

\section{References}

[1] Gherlone M. On the Use of Zigzag Functions in Equivalent Single Layer Theories for Laminated Composite and Sandwich Beams: A Comparative Study and Some Observations on External Weak Layers. J Appl Mech 2013;80:061004.

[2] Sarangan S, Singh BN. Higher-order closed-form solution for the analysis of laminated composite and sandwich plates based on new shear deformation theories. Composite Structures 2016;138:391-403.

[3] Shariyat M. A generalized global-local high-order theory for bending and vibration analyses of sandwich plates subjected to thermo-mechanical loads. International Journal of Mechanical Sciences 2010;52:495-514. doi:10.1016/j.ijmecsci.2009.11.010.

[4] Ghalami-Choobar M, Sadighi M. Investigation of high velocity impact of cylindrical projectile on sandwich panels with fiber-metal laminates skins and polyurethane core. Aerospace Science and Technology 2014;32:142-52.

[5] Mamivand M, Liaghat GH. A model for ballistic impact on multi-layer fabric targets. International Journal of Impact Engineering 2010;37:806-12.

[6] Groh RMJ, Weaver PM. On displacement-based and mixed-variational equivalent single layer theories for modelling highly heterogeneous laminated beams. International Journal of Solids and Structures 2015;59:147-70. 
[7] Azhari F, Boroomand B, Shahbazi M. Explicit relations for the solution of laminated plates modeled by a higher shear deformation theory: Derivation of exponential basis functions. International Journal of Mechanical Sciences 2013;77:301-13. doi:10.1016/j.ijmecsci.2013.10.002.

[8] Tounsi A, Houari MSA, Benyoucef S, Adda Bedia EA. A refined trigonometric shear deformation theory for thermoelastic bending of functionally graded sandwich plates. Aerospace Science and Technology 2013;24:209-20.

[9] Nallim LG, Oller S, Oñate E, Flores FG. A hierarchical finite element for composite laminated beams using a refined zigzag theory. Composite Structures 2017;163:168-84.

[10] Mantari JL, Soares CG. A quasi-3D tangential shear deformation theory with four unknowns for functionally graded plates. Acta Mech 2015;226:625-42.

[11] Afshin M, Sadighi M, Shakeri M. Static Analysis of Cylindrical Sandwich Panels with a Flexible Core and Laminated Composite Face Sheets. Journal of Composite Materials 2010;44:1455-76.

[12] Singh DB, Singh BN. New higher order shear deformation theories for free vibration and buckling analysis of laminated and braided composite plates. International Journal of Mechanical Sciences 2017;131-132:265-77. doi:10.1016/j.ijmecsci.2017.06.053.

[13] Carrera E. Historical review of Zig-Zag theories for multilayered plates and shells. Appl Mech Rev 2003;56:287-308. doi:10.1115/1.1557614.

[14] Ambartsumian SA. On a general theory of anisotropic shells. Journal of Applied Mathematics and Mechanics 1958;22:305-19.

[15] Di Sciuva M. Development of an anisotropic, multilayeréd, shear-deformable rectangular plate element. Computers \& Structures 1985;21:789-96.

[16] Tessler A, DiSciuva M, Gherlone M. Refinement of Timoshenko beam theory for composite and sandwich beams using zigzag kinematics 2007.

[17] Murakami H. Laminated Composite Plate Theory With Improved In-Plane Responses. J Appl Mech 1986;53:661-6. doi:10.1115/1.3171828.

[18] Carrera E. Theories and Finite Elements for Multilayered Plates and Shells: A Unified compact formulation with numerical assessment and benchmarking. ARCO 2003;10:215-96. doi:10.1007/BF02736224.

[19] Carrera E. On the use of the Murakami's zig-zag function in the modeling of layered plates and shells. Computers \& Structures 2004;82:541-54. doi:10.1016/j.compstruc.2004.02.006.

[20] Brischetto S, Carrera E, Demasi L. Improved bending analysis of sandwich plates using a zigzag function. Composite Structures 2009;89:408-15.

[21] Groh RMJ, Weaver PM. A computationally efficient 2D model for inherently equilibrated 3D stress predictions in heterogeneous laminated plates. Part II: Model validation. Composite Structures 2016;156:186-217. doi:10.1016/j.compstruct.2015.11.077.

[22] Groh RMJ, Weaver PM. A computationally efficient 2D model for inherently equilibrated 3D stress predictions in heterogeneous laminated plates. Part I: Model formulation. Composite Structures 2016;156:171-85. doi:10.1016/j.compstruct.2015.11.078.

[23] Rodrigues JD, Roque CMC, Ferreira AJM, Carrera E, Cinefra M. Radial basis functions-finite differences collocation and a Unified Formulation for bending, vibration and buckling analysis of laminated plates, according to Murakami's zig-zag theory. Composite Structures 2011;93:1613-20. doi:10.1016/j.compstruct.2011.01.009.

[24] Kapuria S, Kulkarni SD. An improved discrete Kirchhoff quadrilateral element based on thirdorder zigzag theory for static analysis of composite and sandwich plates. Int J Numer Meth Engng 2007;69:1948-81. doi:10.1002/nme.1836.

[25] Kulkarni SD, Kapuria S. Free vibration analysis of composite and sandwich plates using an improved discrete Kirchhoff quadrilateral element based on third-order zigzag theory. Comput Mech 2008;42:803-24. doi:10.1007/s00466-008-0285-z.

[26] Neves AMA, Ferreira AJM, Carrera E, Cinefra M, Jorge RMN, Soares CMM. Static analysis of functionally graded sandwich plates according to a hyperbolic theory considering Zig-Zag and warping effects. Advances in Engineering Software 2012;52:30-43. doi:10.1016/j.advengsoft.2012.05.005. 
[27] Sahoo R, Singh BN. A new trigonometric zigzag theory for buckling and free vibration analysis of laminated composite and sandwich plates. Composite Structures 2014;117:316-32. doi:10.1016/j.compstruct.2014.05.002.

[28] Pandit MK, Sheikh AH, Singh BN. An improved higher order zigzag theory for the static analysis of laminated sandwich plate with soft core. Finite Elements in Analysis and Design 2008;44:602-10. doi:10.1016/j.finel.2008.02.001.

[29] Groh RMJ, Tessler A. Computationally efficient beam elements for accurate stresses in sandwich laminates and laminated composites with delaminations. Computer Methods in Applied Mechanics and Engineering 2017;320:369-95. doi:10.1016/j.cma.2017.03.035.

[30] Groh RM, Weaver PM, Tessler A. Application of the Refined Zigzag Theory to the modeling of delaminations in laminated composites. NASA Langley Research Center; Hampton, YA, United States; 2015.

[31] Eijo A, Oñate E, Oller S. A numerical model of delamination in composite laminated beams using the LRZ beam element based on the refined zigzag theory. Composite Structures 2013;104:270-80. doi:10.1016/j.compstruct.2013.04.035.

[32] Eijo A, Oñate E, Oller S. Delamination in laminated plates using the 4-noded quadrilateral QLRZ plate element based on the refined zigzag theory. Composite Structures 2014;108:45671. doi:10.1016/j.compstruct.2013.09.052.

[33] Groh RMJ, Weaver PM. Static inconsistencies in certain axiomatic higher-order shear deformation theories for beams, plates and shells. Composite Structures 2015;120:231-45. doi:10.1016/j.compstruct.2014.10.006.

[34] Ghugal YM, Kulkarni SK. Flexural analysis of cross-ply laminated plates subjected to nonlinear thermal and mechanical loadings. Acta Mech 2013;224:675-90.

[35] Şimşek M, Reddy JN. Bending and vibration of functionally graded microbeams using a new higher order beam theory and the modified couple stress theory. International Journal of Engineering Science 2013;64:37-53.

[36] Hibbitt, Karlsson, Sorensen. ABAQUS/standard User's Manual. vol. 1. Hibbitt, Karlsson \& Sorensen; 2001.

[37] Reddy JN. A Simple Higher-Order Theory for Laminated Composite Plates. J Appl Mech 1984;51:745-52.

[38] Chakrabarti A, Chalak HD, Ashraf Iqbal M, Sheikh AH. A new FE model based on higher order zigzag theory for the analysis of laminated sandwich beam with soft core. Composite Structures 2011;93:271-9. doi:10.1016/j.compstruct.2010.08.031.

[39] Pagano NJ. Exact Solutions for Composite Laminates in Cylindrical Bending. Journal of Composite Materials 1969;3:398-411. doi:10.1177/002199836900300304.

[40] Liou W-J, Sun CT. A three-dimensional hybrid stress isoparametric element for the analysis of laminated composite plates. Computers \& Structures 1987;25:241-9. doi:10.1016/00457949(87)90147-7.

[41] Matsunaga H. Interlaminar stress analysis of laminated composite beams according to global higher-order deformation theories. Composite Structures 2002;55:105-14. doi:10.1016/S02638223(01)00134-9.

[42] Bambole AN, Desai YM. Hybrid-interface finite element for laminated composite and sandwich beams. Finite Elements in Analysis and Design 2007;43:1023-36. doi:10.1016/j.finel.2007.06.013. 


\section{Figure Captions}

Fig. 1 Slope change of piece-wise continuous displacement (ZZ phenomenon) and distribution of stress fields through the thickness

Fig. 2 A multilayer composite subjected to general load and its geometry

Fig. 3 A half beam to model three points bending due to symmetry

Fig. 4 Comparison of shear stress transverse obtained using present theory for $\varnothing=$ parabolic and that of [6]

Fig. 5 Comparison transverse shear stress along axis $\mathrm{x}$ for Laminate B obtained using present theory for $\emptyset=$ exponential and that of FEM solution

Fig 6 Comparison of transverse shear stress field through the thickness with that of Another high order ZZT(Chakerberati et al) and 3D elasticity(Pagano)

Fig. 7 Variation of shear stress calculated using present ZZT with various shape functions (See Table 1)

Fig. 8 Variation of transverse shear stress $\tau$ calculated using present ZZT and HSDT and EBDT

Fig. 9 Variation of normal stress $\sigma$ calculated using present ZZT and HSDT and EBDT

Fig. 10 Variation of non-dimensional transverse deflection of Laminate A subjected to sinusoidal load calculated using present ZZT, HSDT, and EBDT

Fig. 11 Comparison of non-dimensional transverse stresses and in-plane displacements of Laminate $A$ at $x=0$ subjected to various loadings calculated using present ZZT, HSDT, FSDT and EBDT with simply supported boundary condition; in-plane displacements - uniform loading (a) in-plane displacements -impulse loading (b) transverse shear stresses - uniform loading (c) transverse shear stresses -uniform loading(d)

Fig. 12 Comparison of non-dimensional transverse stresses and in-plane displacements of Laminate $A$ at $x=L / 4$ subjected to impulse loading calculated using present ZZT, HSDT, FSDT and EBDT with various boundary 
condition; in-plane displacements -simply supported (a) in-plane displacements -clamped (b) transverse shear stresses - simply supported (c) transverse shear stresses -clamped(d)

Fig. 13 Variation of punch force vs midpoint deflection of the beam using present ZZT, HSDT, and EBDT

Figures

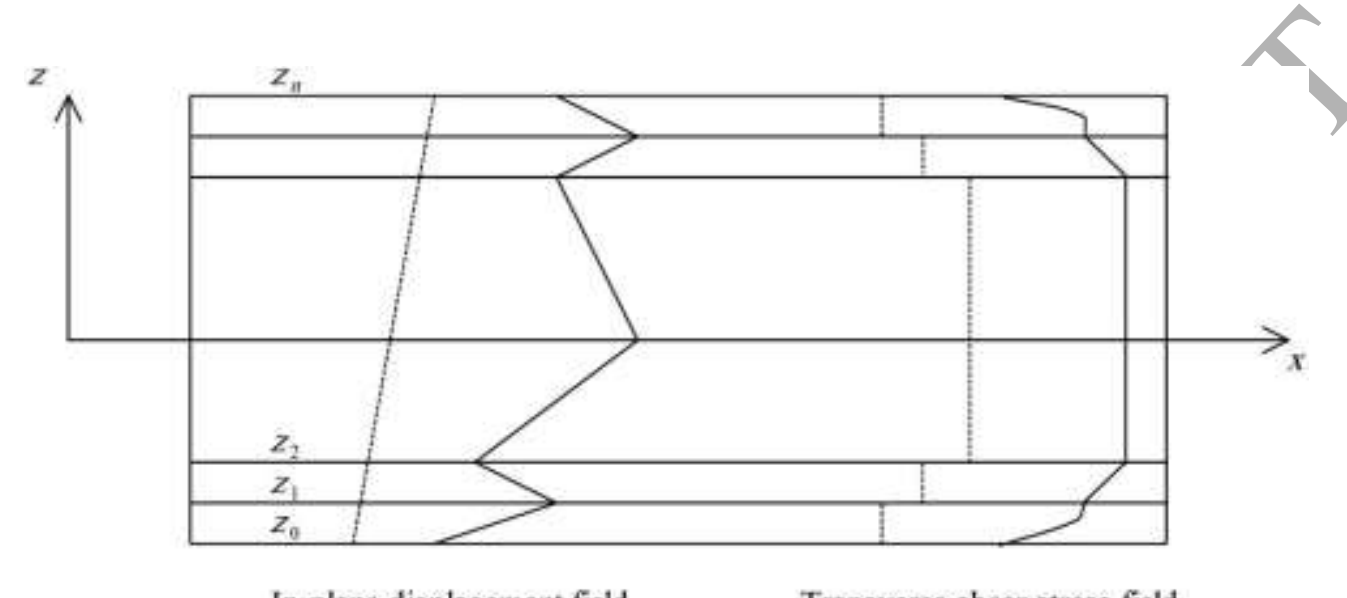

In-plane displacement field Transverse shear stress field

(FSDT(dashed), Exact(solid)) (FSDT(dashed), Exact(solid))

Fig. 1

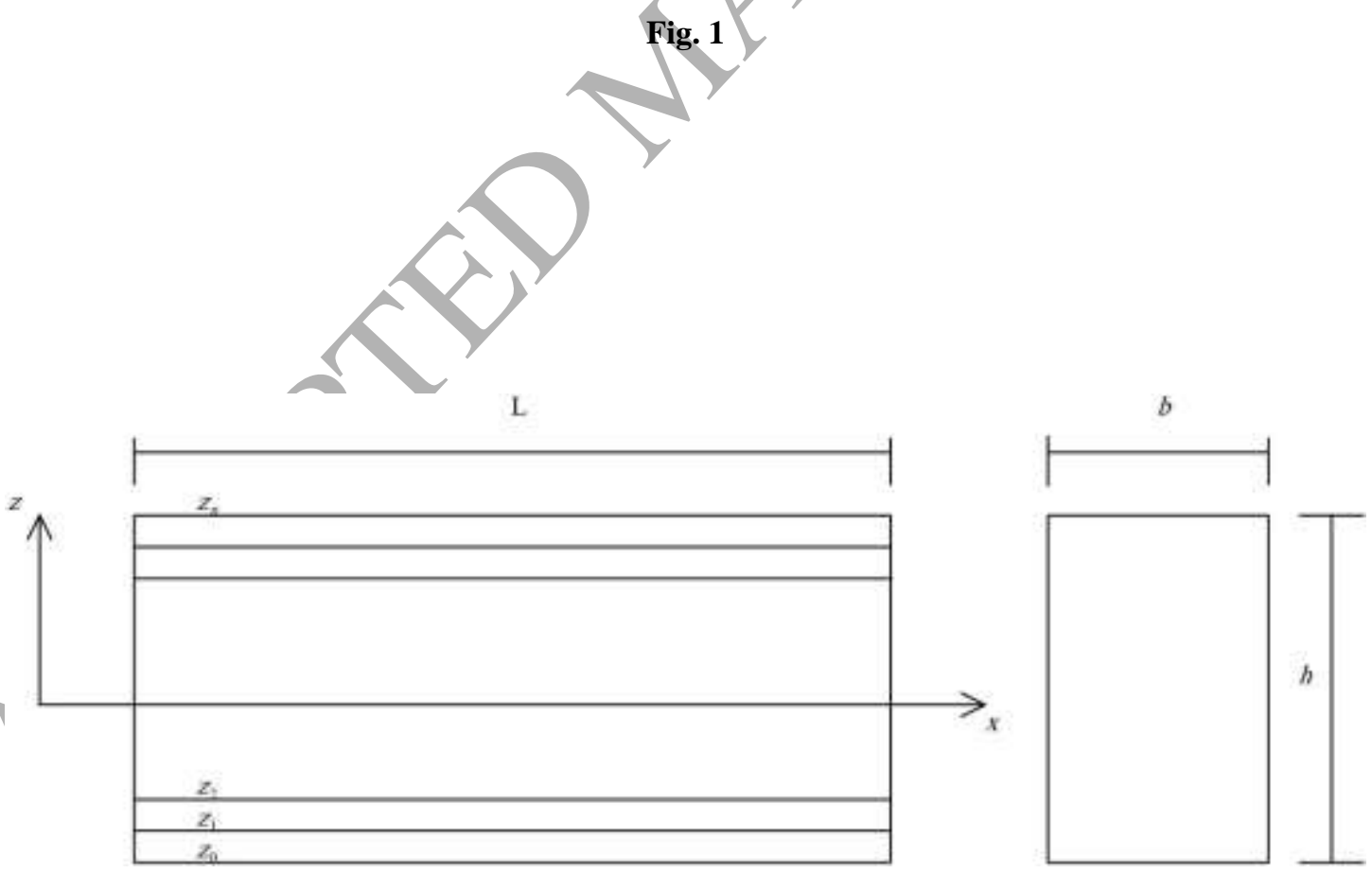

Fig. 2 

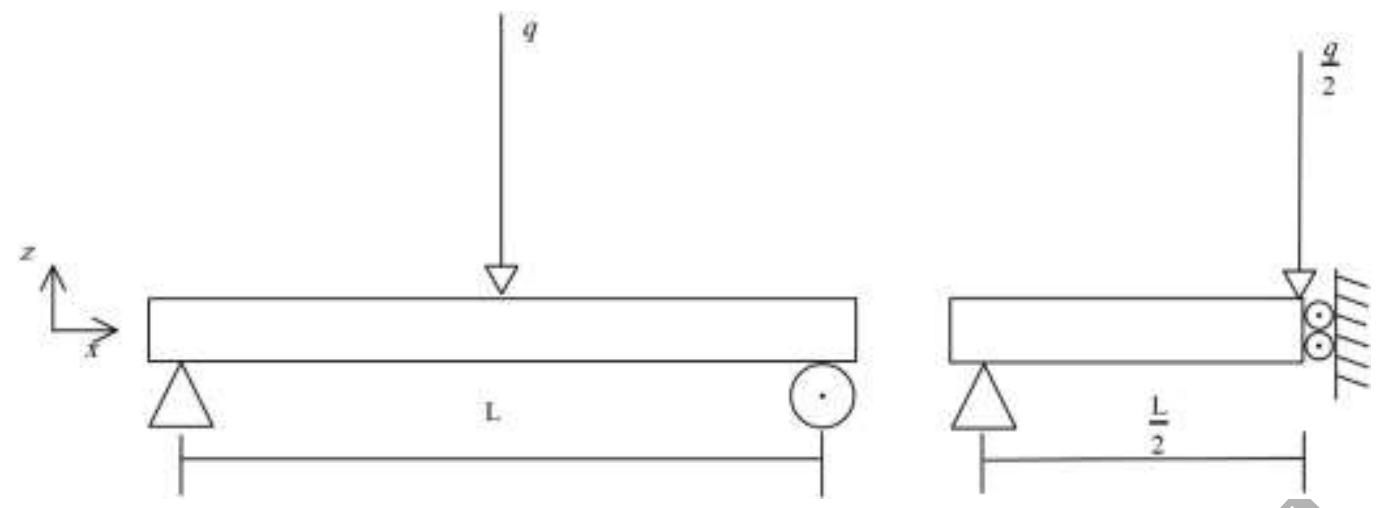

Fig. 3

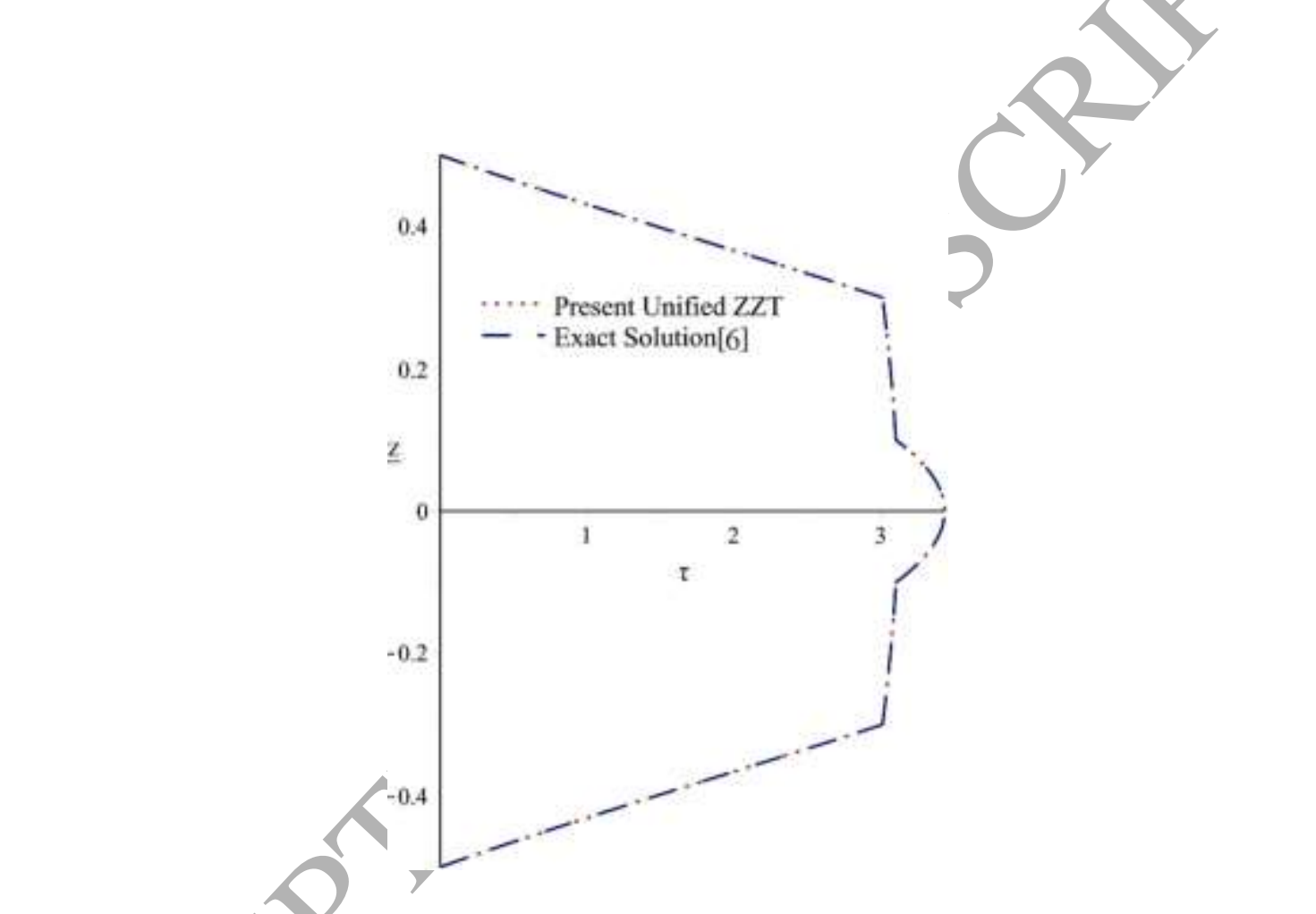

Fig. 4 


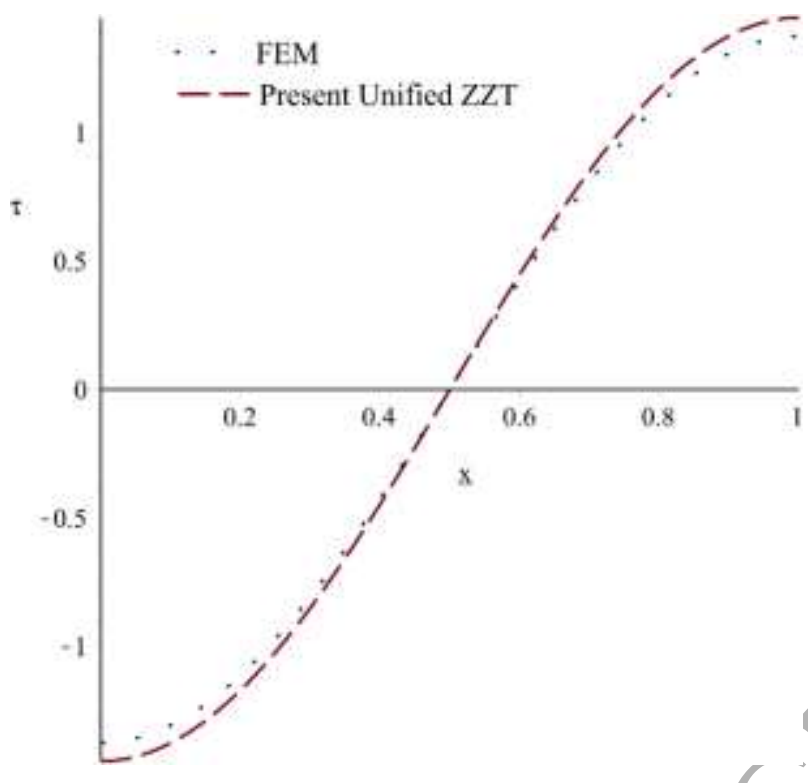

Fig. 5

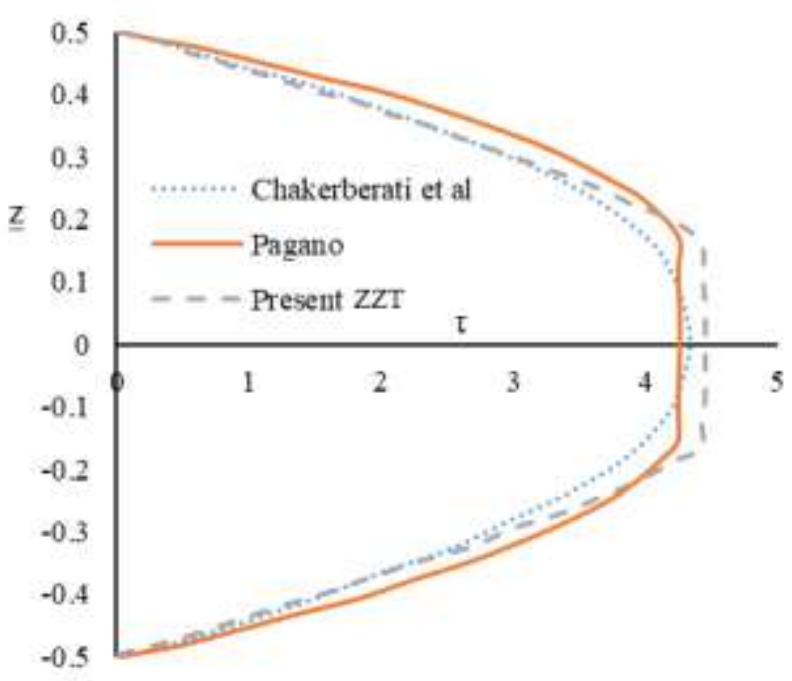

Fig. 6 


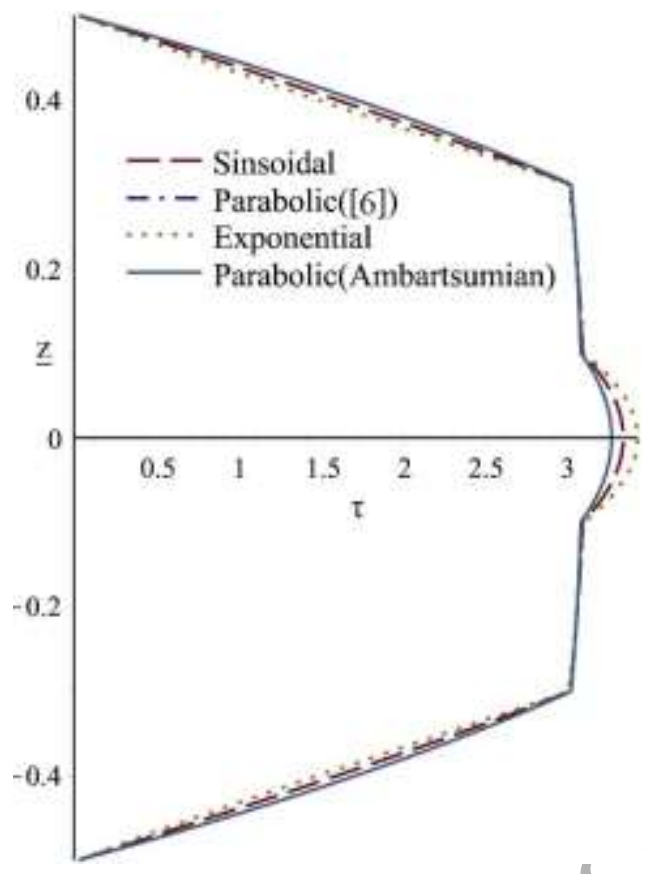

Fig. 7

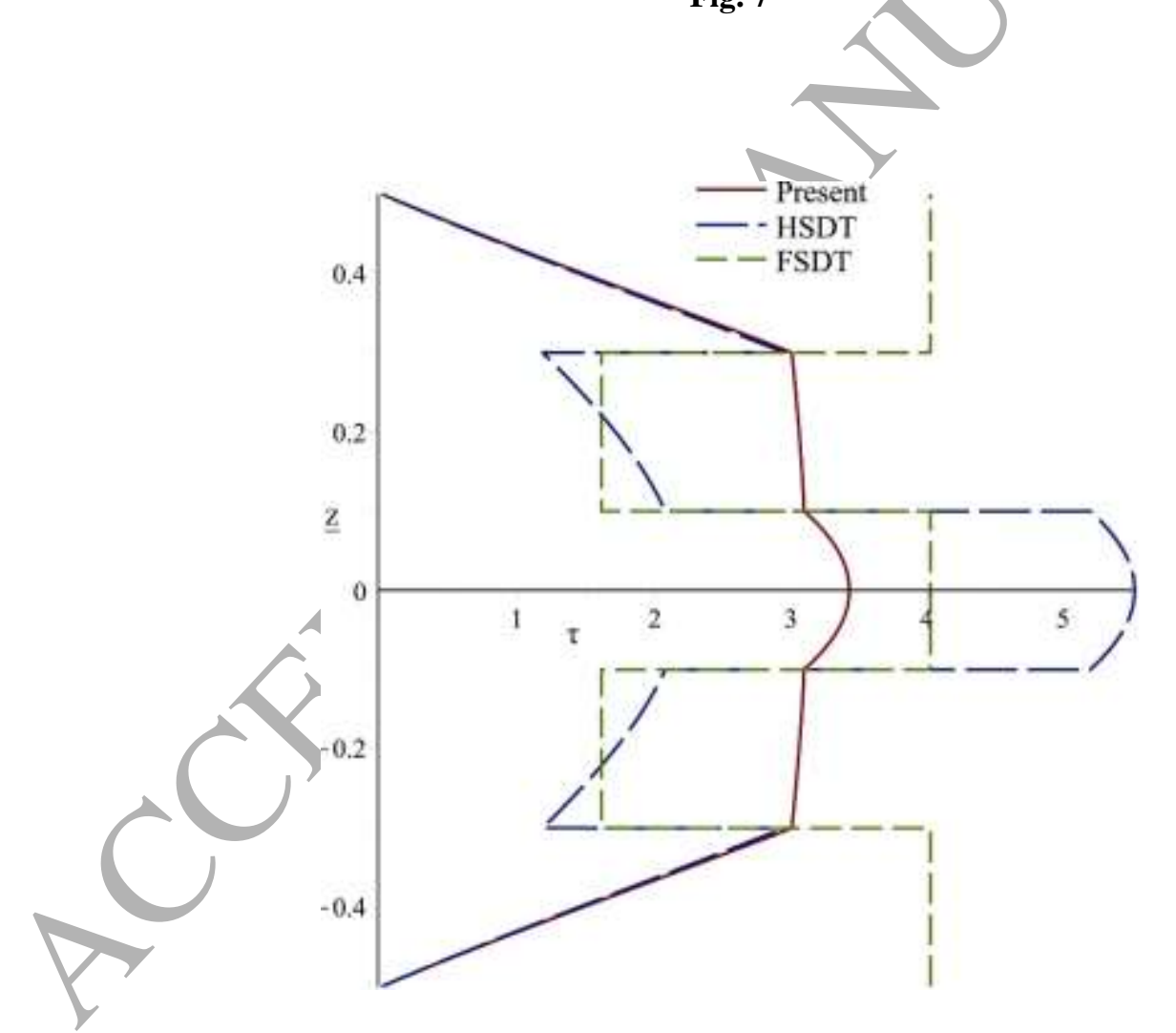

Fig. 8 


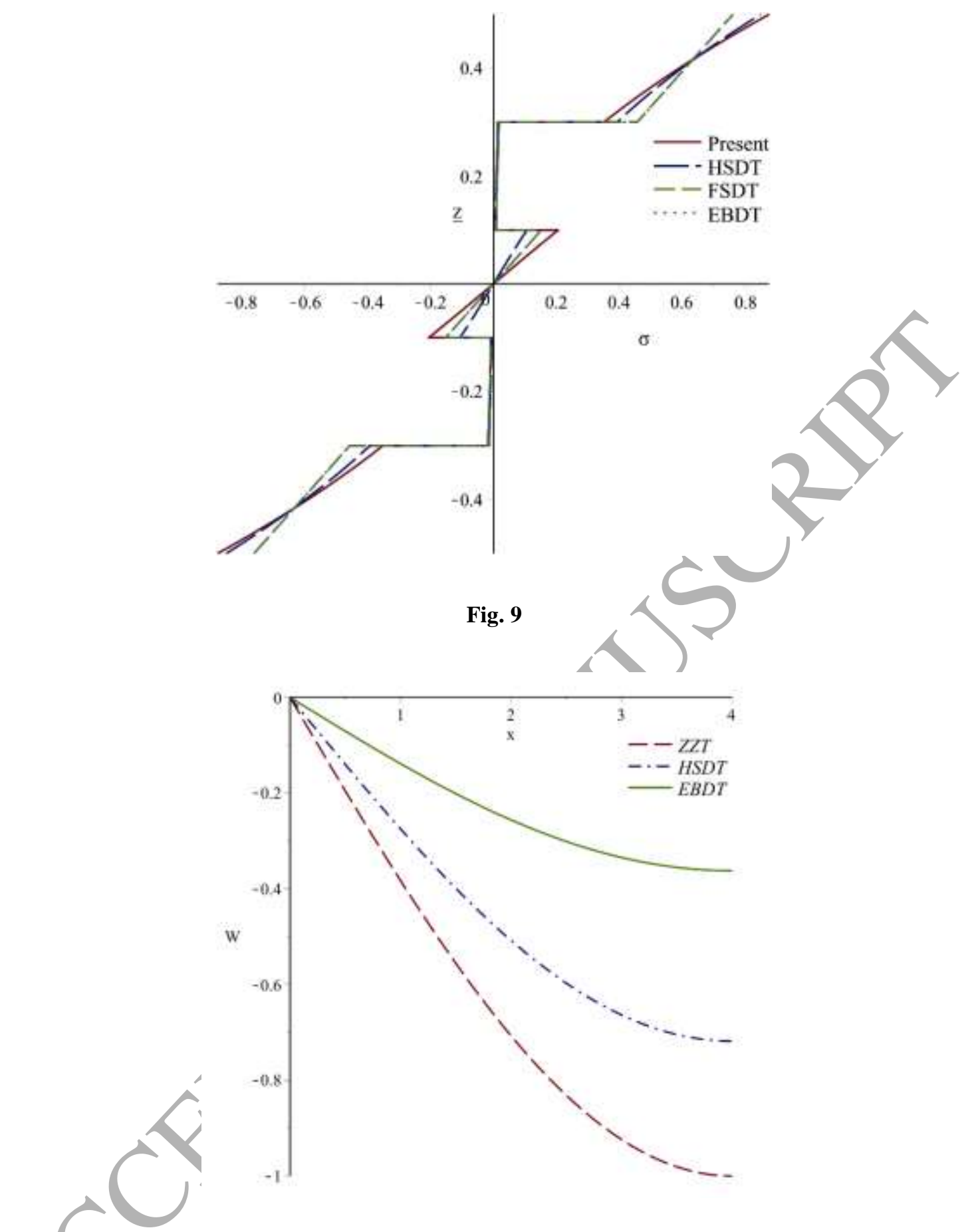

Fig. 10 


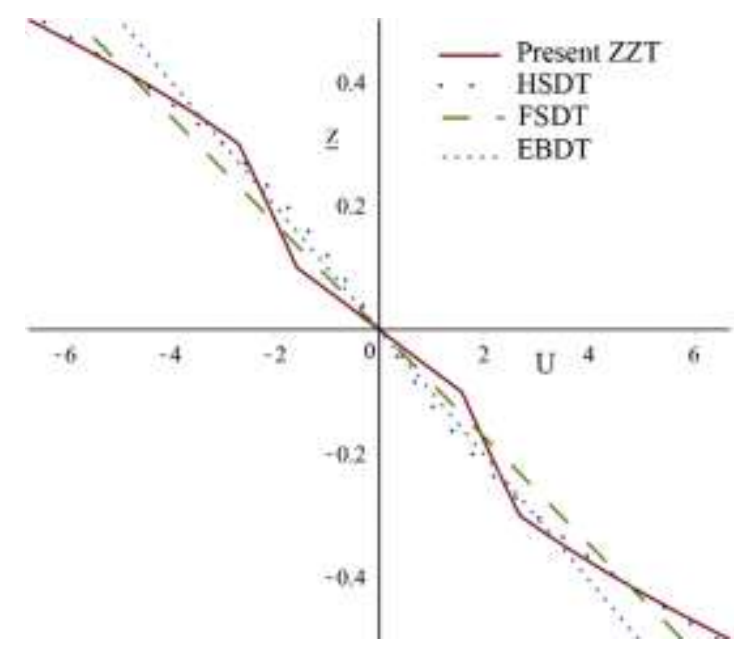

a)

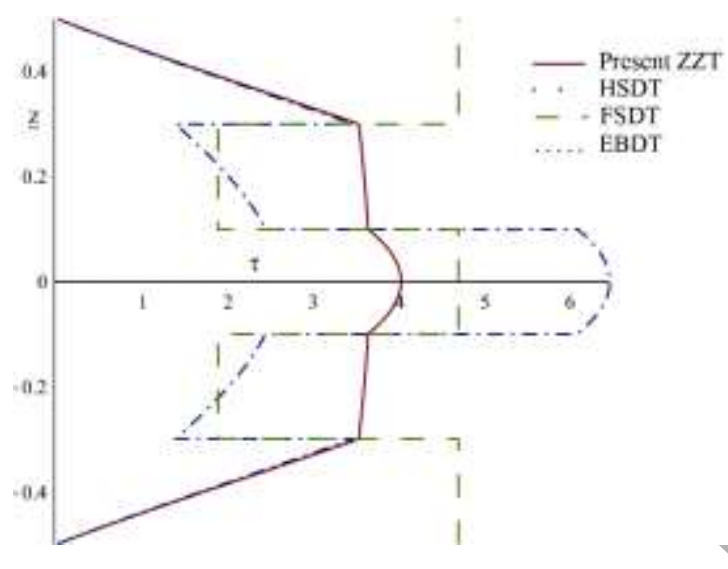

c)

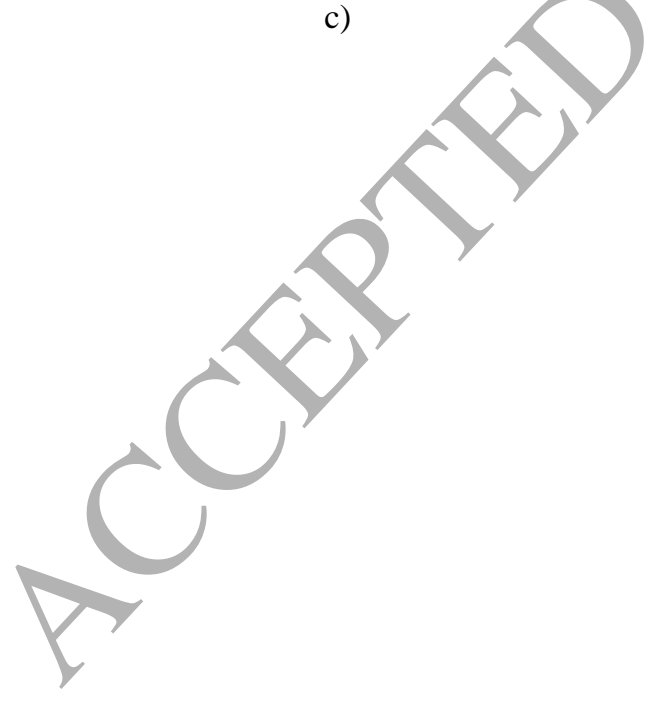

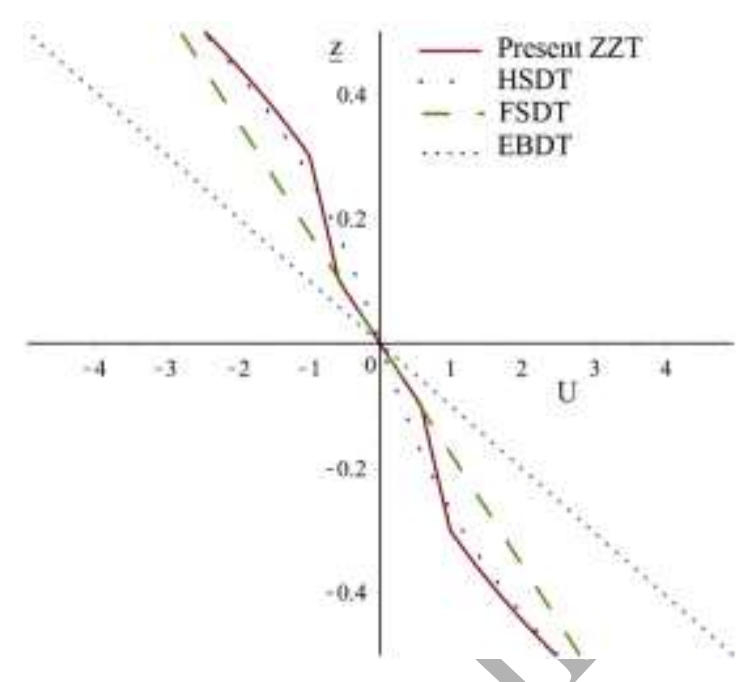

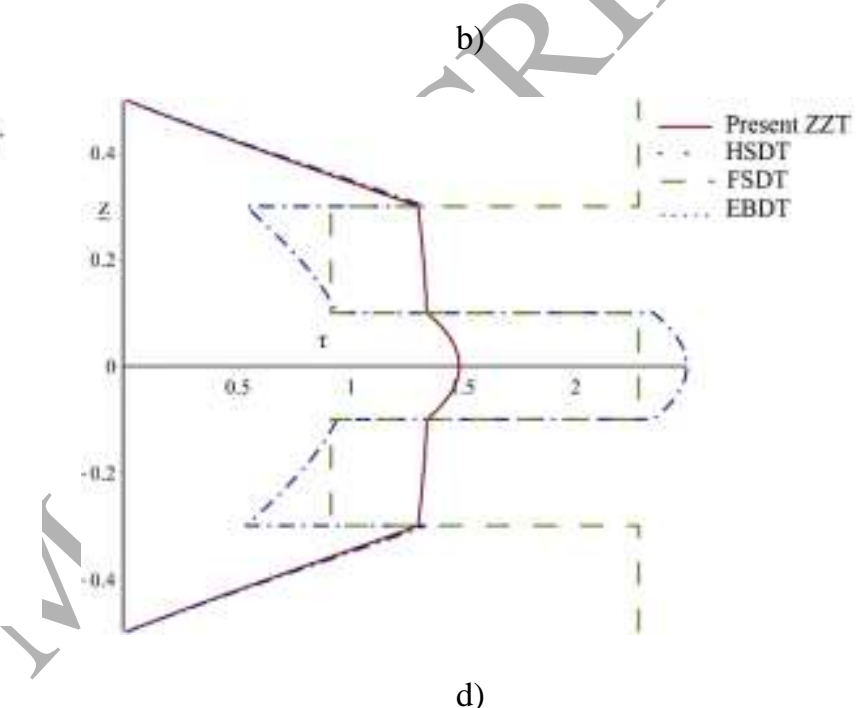

Fig. 11 


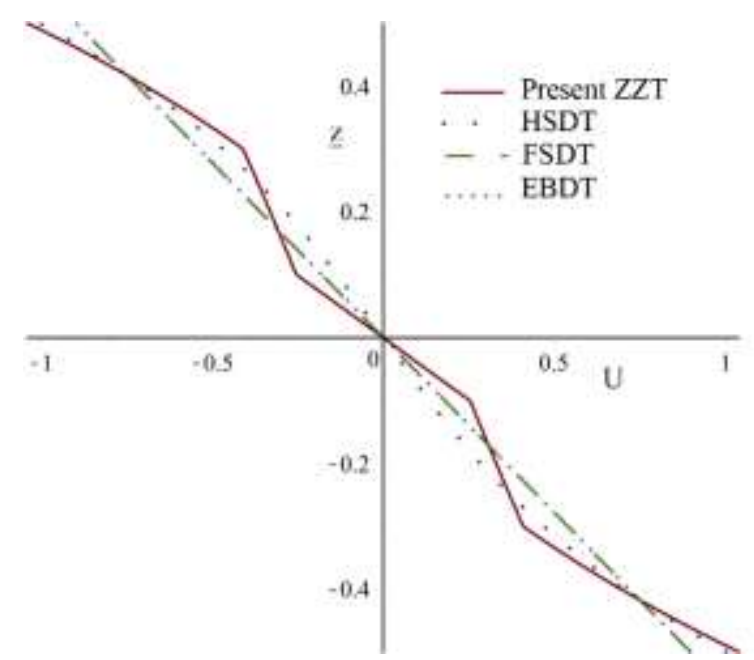

a)

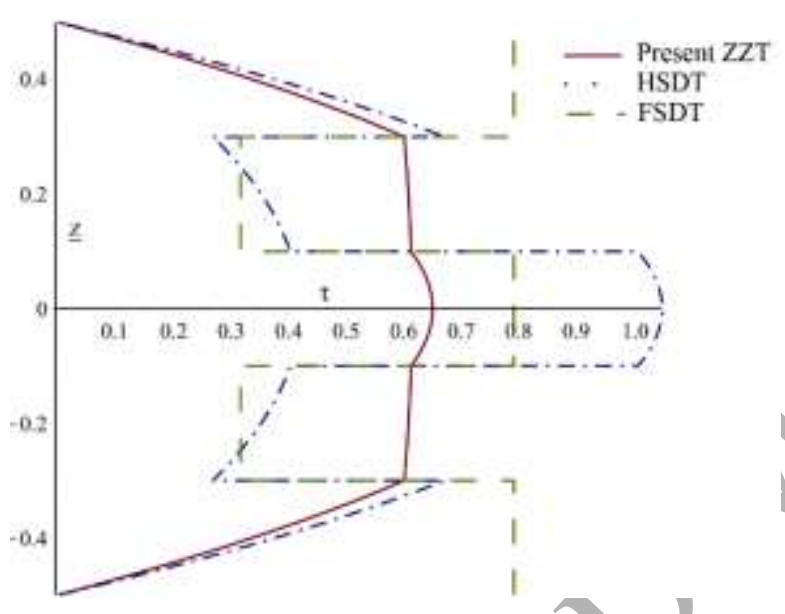

c)

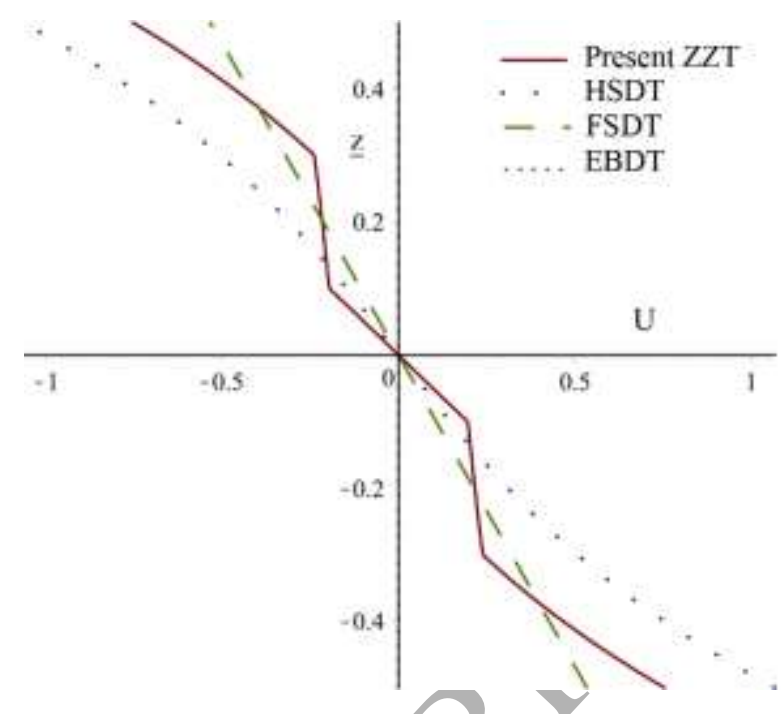

b)

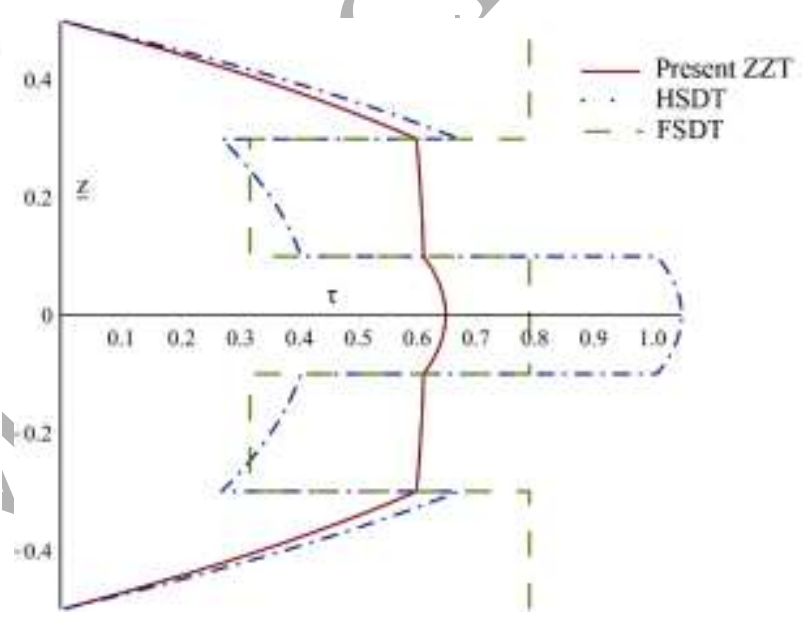

d)

Fig. 12 


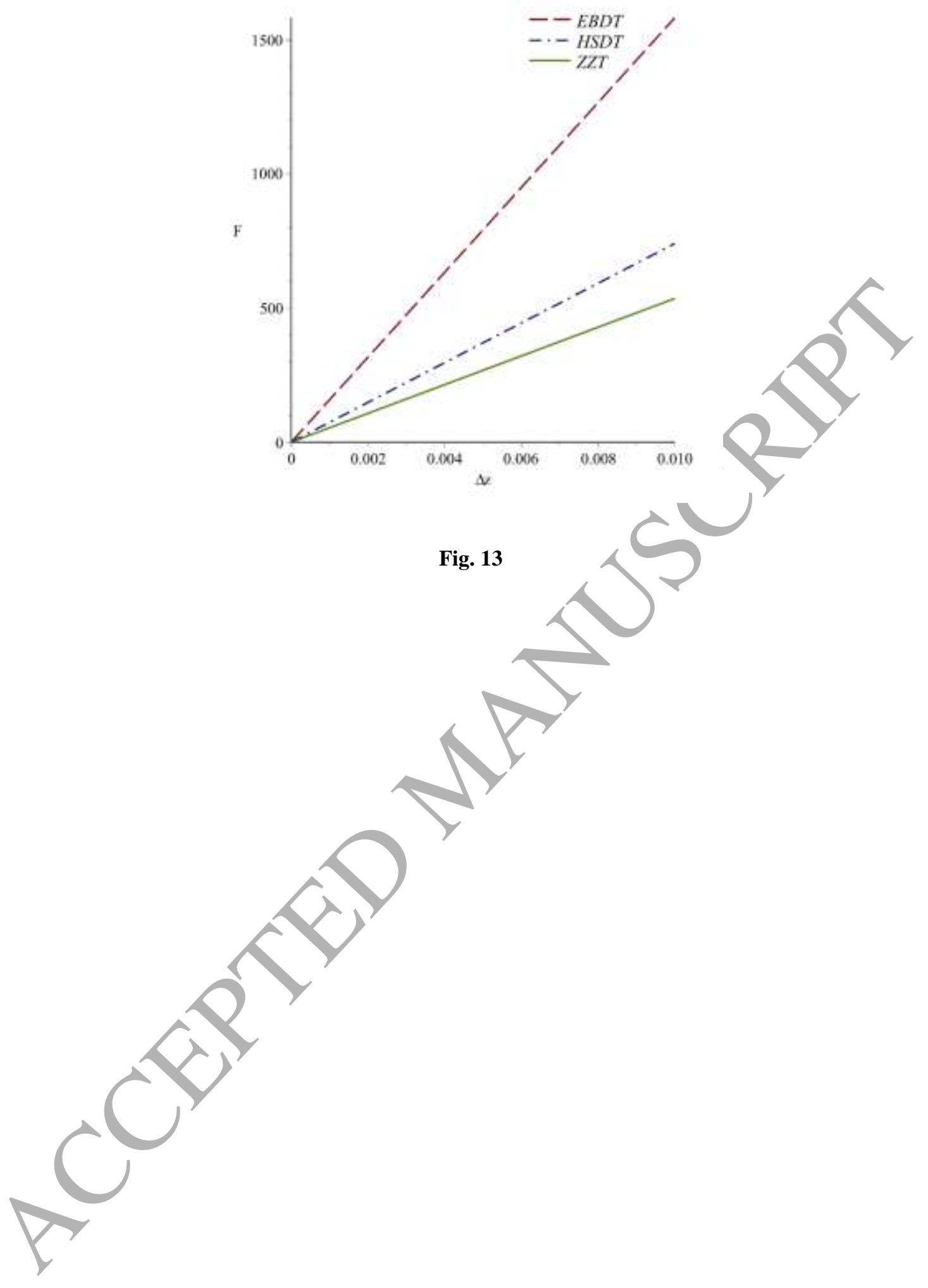


Tables

Table 1 Some shape functions introduced in literature and used in comparison example.

Table 2 Mechanical properties of utilized composite A [6]

Table 3 Mechanical properties of utilized composite B

Table 4 Non-dimensional displacements and stresses for three and five layers symmetric cross-ply laminated beam for aspect ratio 8

Table 5 comparison of non-dimensional stresses and displacements of laminated composite beam for various aspect ratio (l/h) given in Chakrabarti et al [38] with present study

Table 6 Non-dimensional displacements and stresses for isotropic, orthotropic and symmetric cross-ply laminated beam for aspect ratio 10

Table 7 Non-dimensional displacements and stresses for isotropic, orthotropic and symmetric cross-ply laminated beam for aspect ratio 4 
Table 1

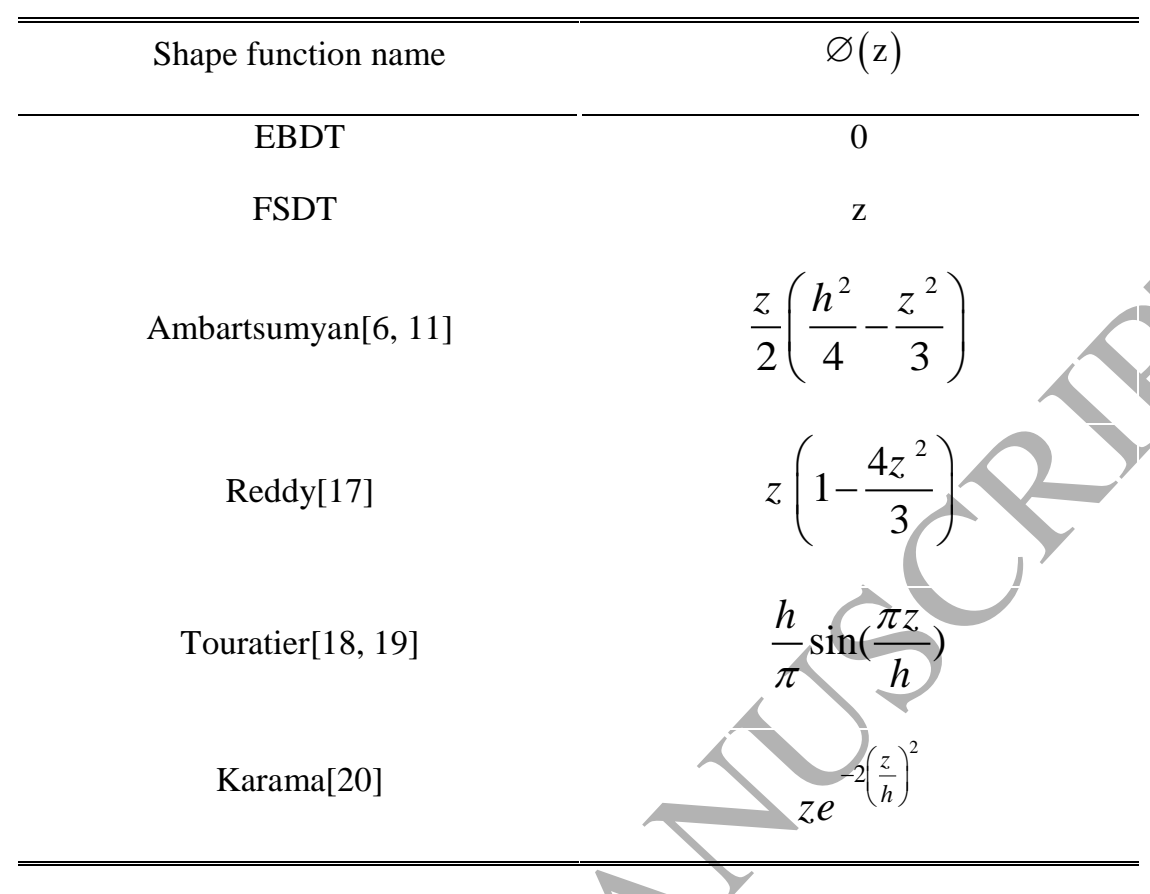

Table 2

\begin{tabular}{cccccc}
\hline \hline $\begin{array}{c}\text { Mechanical } \\
\text { properties }\end{array}$ & $\begin{array}{c}\text { Value } \\
\times 10^{6} \mathrm{psi}\end{array}$ & $\begin{array}{c}\text { Mechanical } \\
\text { properties }\end{array}$ & $\begin{array}{c}\text { Value } \\
\times 10^{6} \mathrm{psi}\end{array}$ & $\begin{array}{c}\text { Mechanical } \\
\text { properties }\end{array}$ & Value \\
\hline$E_{1}$ & 25 & $G_{12}$ & 5 & $v_{12}$ & 0.25 \\
$E_{2}$ & 1 & $G_{13}$ & 5 & $v_{23}$ & 0.25 \\
$E_{3}$ & 1 & $G_{23}$ & 2 & $v_{13}$ & 0.25 \\
\hline \hline
\end{tabular}

Table 3

\begin{tabular}{cclclc}
\hline \hline $\begin{array}{c}\text { Mechanical } \\
\text { properties }\end{array}$ & $\begin{array}{c}\text { Value } \\
(\mathrm{GPa})\end{array}$ & $\begin{array}{c}\text { Mechanical } \\
\text { properties }\end{array}$ & $\begin{array}{c}\text { Value } \\
(\mathrm{GPa})\end{array}$ & $\begin{array}{c}\text { Mechanical } \\
\text { properties }\end{array}$ & Value \\
\hline$E_{1}$ & 241.5 & $G_{12}$ & 5.18 & $v_{12}$ & 0.24 \\
$E_{2}$ & 18.89 & $G_{13}$ & 5.18 & $v_{23}$ & 0.25 \\
$E_{3}$ & 18.89 & $G_{23}$ & 3.45 & $v_{13}$ & 0.24 \\
\hline \hline
\end{tabular}


Table 4

\begin{tabular}{ccccc}
\hline \hline Beam & Theory & $W(L / 2, h / 2)$ & $\sigma_{x}(L / 2, h / 2)$ & $\tau_{x z}(L / 2,0)$ \\
\hline$[0 / 90 / 0]$ & Exact[6] & 0.0116 & 0.7913 & 3.3176 \\
& Parabolic[6] & 0.0116 & 0.7997 & 3.3926 \\
& Present-Sinusoidal & 0.0116 & 0.8036 & 3.4187 \\
& Present-Exponential & 0.0116 & 0.8071 & 3.4410 \\
{$[0 / 90$} & & & & 3.3228 \\
$/ 0 / 90 / 0]$ & & 0.0124 & 0.8672 & 3.2688 \\
& Exact[6] & 0.0124 & 0.8703 & 3.3403 \\
& Present-Sinusoidal & 0.0124 & 0.8725 & 3.4279
\end{tabular}

Table 5

\begin{tabular}{|c|c|c|c|c|c|}
\hline $1 / \mathrm{h}$ & Reference & $W(L / 2, h / 2)$ & $U(L / 2, h / 2)$ & $\tau_{x z}(L / 2,0)$ & $\sigma_{x}(L / 2, h / 2)$ \\
\hline \multirow{3}{*}{100} & Present Unified ZZT & 0.5155 & 8020 & 45.10 & 6315.00 \\
\hline & Chakrabarti et al [38] & 0.5140 & 8020 & 45.23 & 6315.00 \\
\hline & Pagano[39] & 0.5153 & 8040 & 44.15 & 6315.00 \\
\hline \multirow{5}{*}{50} & Present Unified ZZT & 0.5335 & 1009 & 22.52 & 1587.90 \\
\hline & Chakrabarti et al [38] & 0.5270 & 1008 & 22.46 & 1587.07 \\
\hline & Liou and sun[40] & 0.5270 & - & - & - \\
\hline & Pagano[39] & 0.5283 & 1010 & 22.05 & 1587.00 \\
\hline & & $1-07$ & & & \\
\hline \multirow{5}{*}{20} & Present Unified ZZT & 0.6587 & 67.10 & 8.98 & 264.22 \\
\hline & Chakrabarti et al [38] & 0.6176 & 66.86 & 8.90 & 263.19 \\
\hline & Lee and $\mathrm{Liu}[40]$ & 0.6173 & - & 8.74 & - \\
\hline & Matsunaga[41] & 0.6150 & - & 8.75 & - \\
\hline & Pagano[39] & 0.6186 & 66.95 & 8.74 & 263.20 \\
\hline \multirow{5}{*}{10} & Present Unified ZZT & 1.0050 & 9.5240 & 4.44 & 74.99 \\
\hline & Chakrabarti et al [38] & 0.9329 & 9.3480 & 4.32 & 73.61 \\
\hline & Bambole and desai[42] & 0.9321 & - & 4.25 & 73.81 \\
\hline & Liou and sun[40] & 0.9315 & - & - & - \\
\hline & Pagano[39] & 0.9357 & 9.3470 & 4.23 & 73.66 \\
\hline
\end{tabular}


Table 6

\begin{tabular}{|c|c|c|c|c|c|c|c|}
\hline \multirow[b]{2}{*}{ Beam } & \multicolumn{3}{|l|}{ Theory } & \multirow[b]{2}{*}{$U(L / 2, h / 2)$} & \multirow[b]{2}{*}{$W(L / 2, h / 2)$} & \multirow[b]{2}{*}{$\sigma_{x}(L / 2, h / 2)$} & \multirow[b]{2}{*}{$\tau_{x z}(L / 2,0)$} \\
\hline & & $\frac{D^{\gamma 2} \pi^{2}}{D J L^{2}}$ & $\frac{D^{\gamma \gamma} \pi^{2}}{J L^{2}}$ & & & & \\
\hline \multirow{2}{*}{$\begin{array}{l}\text { Isotropic } \\
E=E_{1}\end{array}$} & Present & 0.0210 & 0.0213 & 1.8151 & 11.8632 & 0.3071 & 0.0436 \\
\hline & HSDT & & & 1.8024 & 11.7805 & 0.3050 & 0.0433 \\
\hline \multirow{2}{*}{$v=v_{12}$} & FSDT & & & 1.7961 & 11.7806 & 0.3039 & 0.0347 \\
\hline & EBDT & & & 1.7961 & 11.5376 & 0.3039 & 0 \\
\hline \multirow[t]{4}{*}[0]{$_{5}$} & Present & 0.4947 & 0.5006 & 0.0963 & 0.8533 & 38311 & 0.0502 \\
\hline & HSDT & & & 0.0827 & 0.7325 & 0.3288 & 0.0431 \\
\hline & FSDT & & & 0.0764 & 0.7339 & & 0.0347 \\
\hline & EBDT & & & 0.0764 & 0.4910 & & - \\
\hline \multirow{4}{*}{$\begin{array}{c}{[0 / 90} \\
/ 0 / 90 / 0]\end{array}$} & Present & 0.6645 & 0.6718 & 0.1177 & 1.1474 & 0.4680 & 0.0420 \\
\hline & HSDT & & & 0.1022 & 0.9379 & 0.4064 & 0.0603 \\
\hline & FSDT & & & 0.0955 & 0.9332 & 0.3798 & 0.0456 \\
\hline & EBDT & & & 0.0955 & 0.6135 & 0.3798 & - \\
\hline \multirow[b]{2}{*}{ Beam } & Theory & $D^{\gamma 2} \pi^{2}$ & $D^{\gamma \gamma}$ & & & & \\
\hline & & $D J L^{2}$ & & $/ 2$ & $W(L / 2, h / 2)$ & $\sigma_{x}(L / 2, h / 2)$ & $\tau_{x z}(L / 2,0)$ \\
\hline \multirow[t]{4}{*}{ Isotropic } & Present & 0.1315 & & 0.7285 & 13.5551 & 0.3242 & 0.0995 \\
\hline & HSDT & & & 0.6979 & 12.9854 & 0.3106 & 0.0953 \\
\hline & FSDT & & & 0.6829 & 12.9878 & 0.3039 & 0.0763 \\
\hline & EBDT & & & 0.6829 & 11.4774 & 0.3039 & - \\
\hline \multirow[t]{4}{*}[0]{$_{5}$} & Present & & 3.1287 & 0.0883 & 3.9501 & 0.9240 & 0.1870 \\
\hline & HSDT & & & 0.0435 & 1.9452 & 0.4550 & 0.0921 \\
\hline & FSDT & & & 0.0290 & 1.9988 & 0.3039 & 0.0763 \\
\hline & & & & 0.0290 & 0.4884 & 0.3039 & - \\
\hline \multirow{4}{*}{$\begin{array}{c}{[0 / 90} \\
/ 0 / 90 / 0]\end{array}$} & Present & 4.1534 & 4.1991 & 0.1018 & 5.4400 & 1.0648 & 0.1416 \\
\hline & HSDT & & & 0.0519 & 2.5867 & 0.5430 & 0.1300 \\
\hline & FSDT & & & 0.0363 & 2.5976 & 0.3798 & 0.1005 \\
\hline & EBDT & & & 0.0363 & 0.6103 & 0.3798 & - \\
\hline
\end{tabular}




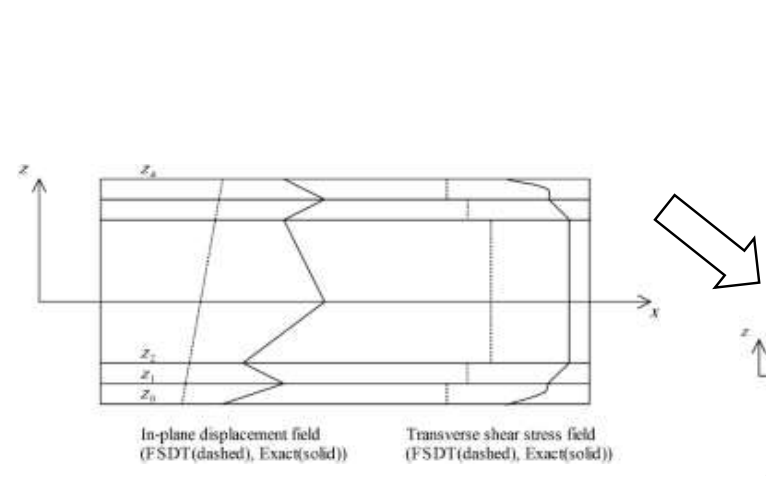

Zig-Zag phenomenon in transversely anisotropic laminate
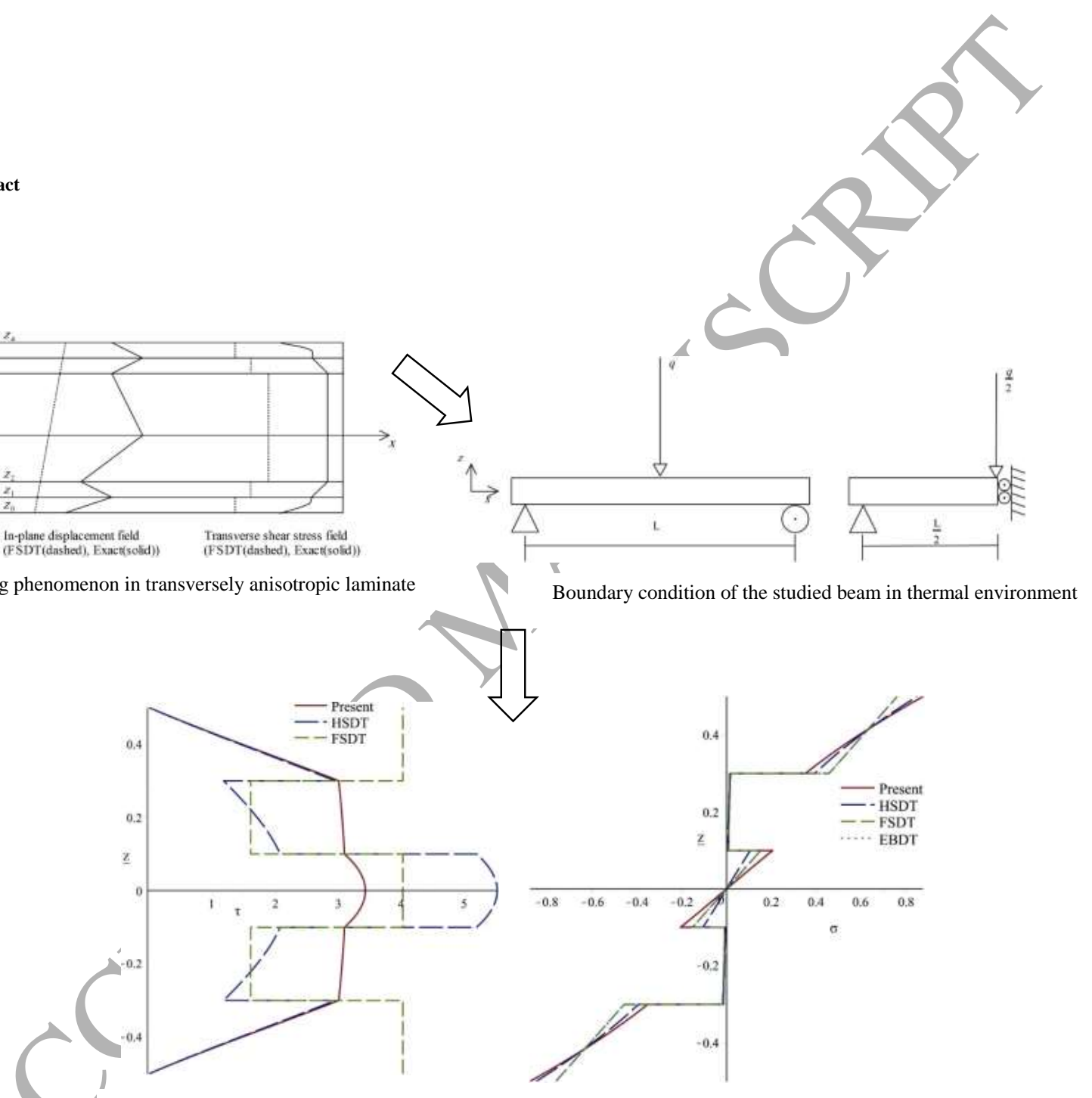

Transverse shear stress and normal stress for different theories (Present, HSDT, FSDT, EBDT) 